\title{
Estimation of tropical cyclone wind hazards in coastal regions of China
}

\author{
Genshen Fang ${ }^{1,2}$, Lin Zhao ${ }^{1,3}$, Shuyang Cao ${ }^{1,3}$, Ledong Zhu ${ }^{1,3}$, and Yaojun Ge ${ }^{1,3}$ \\ ${ }^{1}$ State Key Laboratory of Disaster Reduction in Civil Engineering, Tongji University, Shanghai 200092, China \\ ${ }^{2}$ Glenn Department of Civil Engineering, Clemson University, Clemson, SC 29634, USA \\ ${ }^{3}$ Key Laboratory of Transport Industry of Wind Resistant Technology for Bridge Structures, \\ Tongji University, Shanghai 200092, China
}

Correspondence: Lin Zhao (zhaolin@ tongji.edu.cn)

Received: 9 November 2019 - Discussion started: 20 January 2020

Revised: 17 April 2020 - Accepted: 9 May 2020 - Published: 5 June 2020

\begin{abstract}
Coastal regions of China feature high population densities as well as wind-sensitive structures and are therefore vulnerable to tropical cyclones (TCs) with approximately six to eight landfalls annually. This study predicts TC wind hazard curves in terms of design wind speed versus return periods for major coastal cities of China to facilitate TC-wind-resistant design and disaster mitigation as well as insurance-related risk assessment. The $10 \mathrm{~min}$ wind information provided by the Japan Meteorological Agency (JMA) from 1977 to 2015 is employed to rebuild TC wind field parameters (radius of maximum winds $R_{\mathrm{max}, \mathrm{s}}$ and shape parameter of radial pressure profile $B_{\mathrm{S}}$ ) at surface level using a height-resolving boundary layer model. These parameters will be documented to develop an improved JMA dataset. The probabilistic behaviors of historical tracks and wind field parameters at the first time step within a $500 \mathrm{~km}$ radius subregion centered at a site of interest are examined to determine preferable probability distribution models before stochastically generating correlated genesis parameters utilizing the Cholesky decomposition method. Recursive models are applied for translation speed, $R_{\mathrm{max}, \mathrm{s}}$ and $B_{\mathrm{S}}$ during the TC track and wind field simulations. Site-specific TC wind hazards are studied using 10000 -year Monte Carlo simulations and compared with code suggestions as well as other studies. The resulting estimated wind speeds for northern cities (Ningbo and Wenzhou) under a TC climate are higher than code recommendations, while those for southern cities (Zhanjiang and Haikou) are lower. Other cities show a satisfactory agreement with code provisions at the height of $10 \mathrm{~m}$. Some potential reasons for these findings are discussed to emphasize
\end{abstract}

the importance of independently developing hazard curves of TC winds.

\section{Introduction}

Tropical cyclones (TCs) are rapidly rotating storms characterized by strong winds, heavy rain, high storm surges and even devastating tornadoes. They inflict tremendous damage on property and considerable loss of human life and pose threats to flexible structures in coastal areas (Done et al., 2020). In the western Pacific basin, TCs form throughout the year. It is the most active TC basin in the world, producing more than 30 storms annually, accounting for almost onethird of the global total (Knapp et al., 2010; Yang and Chen, 2019). The southeast China coastal area has long coastlines and numerous islands, which feature high population densities as well as many wind-sensitive structures including highrise buildings and long-span bridges (Tao et al., 2018; Tao and Wang, 2019). It is a TC-prone region, with an average of six to eight TC landfalls per year. It has been estimated that more than 1600 fatalities and CNY 80 billion of direct economic loss can be attributed to TCs and subsequent floods in 2006 alone in coastal regions of China (Liu et al., 2009), demonstrating that this area is extremely vulnerable to TC damage. Accordingly, it is an issue of great importance to analyze TC wind hazards to support wind-resistant design as well as disaster mitigation and insurance-related risk assessment. 
Unlike non-TC winds such as monsoons, TCs are moving rotating storms with a small occurrence rate at a specific location. Moreover, wind anemometers are usually vulnerable to damage during strong typhoon events, making the record of historically observed winds an unreliable predictor for design wind speed based on statistical distribution models. The largest yearly wind speed dataset derived from both non-TC and TC winds is considered to be not well behaved because the contribution of each wind speed to describe the probabilistic behavior of the extreme winds is inhomogeneous (Simiu and Scanlan, 1996). An alternative approach, called stochastic simulation or Monte Carlo simulation, introduced in the 1970s by some pioneering studies (e.g., Russell and Schueller, 1974; Batts et al., 1980), has been widely adopted to stochastically generate a large number of wind speed samples using historical data-based probability distributions of several key field parameters. In order to achieve TC hazard assessment by Monte Carlo simulation, the circular subregion method (CSM) was developed by Georgiou (1985) and later employed by Vickery and Twisdale (1995), Xiao et al. (2011), and Li and Hong (2015). The CSM uses the circled historical track information centered on the site of interest to characterize the statistics of some TC parameters before conducting storm simulation and wind speed prediction. This is a site-specific approach. The stateof-the-art empirical full-track technique was first developed by Vickery et al. (2000b) and followed by FEMA (Federal Emergency Management Agency, 2015) as well as the ASCE 7-16 loads standard (ASCE STANDARD, 2017) and Li and Hong (2016), which simulates the TC tracks as well as the intensity in terms of a relative intensity index from genesis to lysis, facilitating the TC risk assessments for the whole coastal region. Although the full-track model is preferable for modeling the TC hazards along the whole coastline, the CSM is widely used for some site-specific TC risk studies and can be easily updated and improved by supplementary observations. This is also adopted in this study.

During TC wind estimation, the parametric TC wind field model has been commonly adopted and has been continuously improved over the past several decades based on the ever increasing number of observation data. This model is considered to be more economical with time and even more accurate in predicting TC wind velocity compared with some meteorological models. Some pioneering studies on parametric TC wind field modeling have been performed since the 1980s (Batts et al., 1980; Georgiou, 1985; Vickery et al., 2000a, 2009; Nederhoff et al., 2019; Arthur, 2019). These studies employed a gradient wind speed model solved by the atmospheric balance equation of a stationary storm coupled with a depth-averaged (Vickery et al., 2000a) or a semiempirical observation-based boundary layer vertical profile model (Vickery et al., 2009). In recent years, with advances in computing capacity, another more sophisticated physical model has received intensive attention. This is the so-called heightresolving model, in which the boundary layer wind field is solved semianalytically based on 3D Navier-Stokes equations (Meng et al., 1995; Kepert, 2010; Snaiki and Wu, 2017; Fang et al., 2018a). This is of great help in interpreting the underlying physics of the TC boundary layer.

Conventionally, wind field parameters such as the radius of maximum wind speed $R_{\max }$ and shape parameter of radial pressure profile $B$ were statistically modeled as functions of surface central pressure deficit, TC eye center latitude and sea surface temperature (Vickery et al., 2000b; Vickery and Wadhera, 2008; Xiao et al., 2011; Zhao et al., 2013; FEMA, 2015; Fang et al., 2018b). This facilitated TC-related hazard assessment by carrying out a large number of scenarios using a Monte Carlo algorithm since the historical track information is readily available in each best-track dataset. However, the correlations between these parameters were not very strong, as shown by Vickery et al. (2000b), with all coefficients of determination less than 0.30 . The auto correlations of $R_{\max }$ as well as $B$ between different time steps in these studies were usually propagated from surface pressure deficit and sea surface temperature, which were integrated with a term of relative intensity and modeled by a recursive model. Moreover, the cross-adoption of these parameter models in different basins could cause some undesired results since they are always region dependent due to differences among macroscopic atmospheric thermodynamic environments.

In this study, wind field information of a $10 \mathrm{~min}$ time duration provided by the best-track dataset of the Japan Meteorological Agency (JMA) was adopted to develop a dataset of $R_{\max }$ and $B$ at surface level $\left(R_{\max , \mathrm{s}}\right.$ and $\left.B_{\mathrm{s}}\right)$ using a height-resolving wind field model. Then the TC design wind speed was predicted by following the procedures illustrated in Fig. 1. Based on the historical track information extracted from the JMA dataset within a circular subregion with a radius of $500 \mathrm{~km}$ centered at the site of interest, the preferable probabilistic distributions of six genesis parameters at the first time step, the position of the first track dot $\left(\alpha_{0}\right)$, heading direction $\left(\theta_{\mathrm{T} 0}\right)$, central pressure difference $\left(\Delta P_{0}\right)$, translation speed $\left(V_{\mathrm{T} 0}\right), R_{\mathrm{max}, \mathrm{s} 0}$ and $B_{\mathrm{s} 0}$ were determined before performing the correlation analyses. Site-specific recursive models of translation speed as well as of $R_{\max , \mathrm{s} 0}$ and $B_{\mathrm{S} 0}$ were developed using the track information within the circular subregion. Finally, 10 000-year Monte Carlo simulations were conducted to investigate the TC wind hazard for 10 coastal cities of China.

\section{Statistical characteristics of TC tracks}

\subsection{JMA best-track dataset}

In the western Pacific basin $\left(0-60^{\circ} \mathrm{N}, 100-180^{\circ} \mathrm{E}\right)$, the Japan Meteorological Agency (JMA) serves as the Regional Specialized Meteorological Center (RSMC TokyoTyphoon Center, 2018), as specified by the World Meteorological Organization (WMO). As such, it is responsi- 


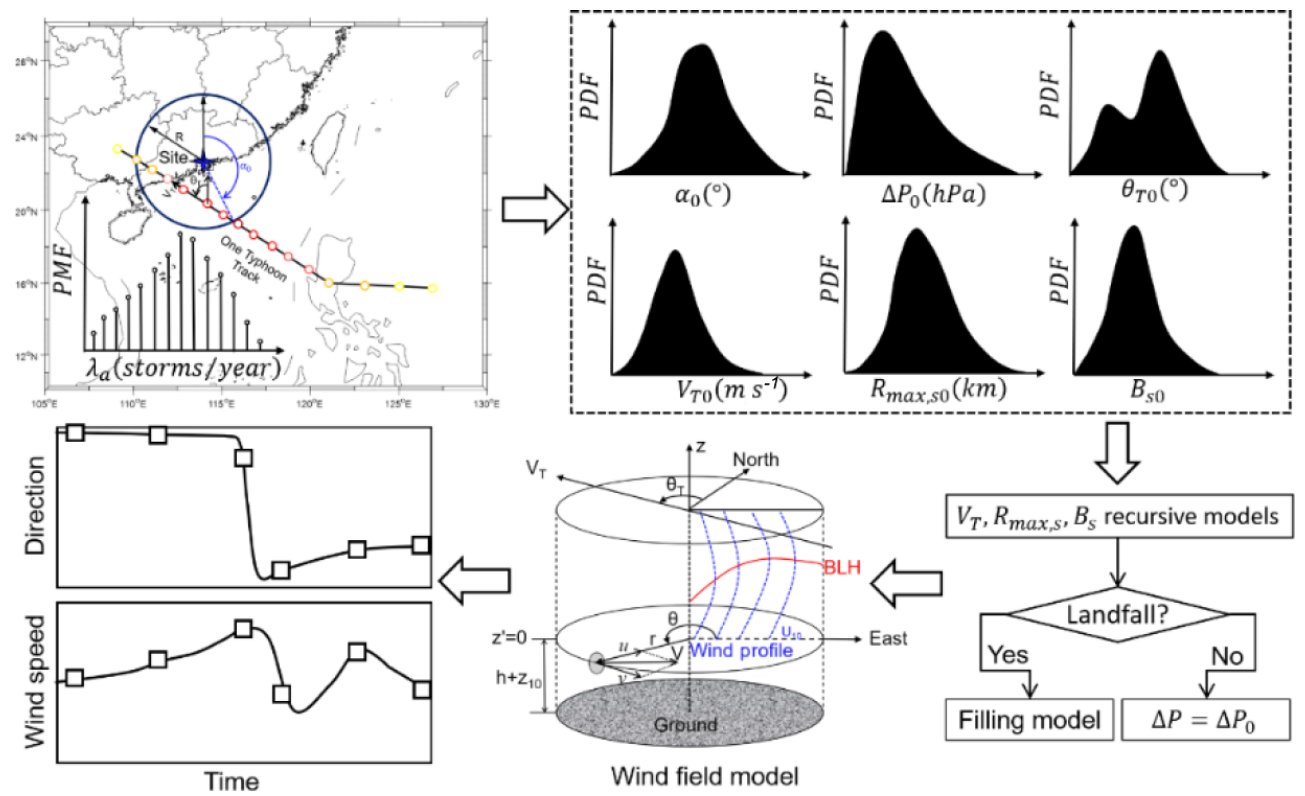

Figure 1. Overview of circular subregion method used in this study.

ble for forecasting, naming, tracking, distributing warnings of and issuing advisories on TCs. Accordingly, the JMA has been publicly releasing best-track datasets of TCs in the western Pacific basin since 1951. These datasets contain not only some basic track information of TCs in terms of latitude and longitude of TC eye centers as well as dates and times but also some wind speed information including minimum surface central pressure $\left(P_{\mathrm{cs}}\right)$, maximum sustained surface wind speed $\left(V_{\max , \mathrm{s}}\right)$ and 50 - or 30-knot ( $1 \mathrm{knot}=0.514 \mathrm{~m} \mathrm{~s}^{-1}$ ) wind radii estimated from surface observation, ASCAT observation and low-level cloud motion satellite images. Although some other organizations issue their own track dataset of TCs for the western $\mathrm{Pa}$ cific basin (Ying et al., 2014), such as the China Meteorological Administration (CMA), Joint Typhoon Warning Center (JTWC), Hong Kong Observatory (HKO) and International Best Track Archive for Climate Stewardship (IBTrACS) project, there are some inconsistencies among these datasets that should be carefully considered. In addition to differences in TC track information and annual TC frequencies, two typical TC intensity representations, i.e. $P_{\mathrm{cs}}$ and $V_{\text {max,s }}$, show inconsistency from agency to agency, as discussed by Song et al. (2010). Generally, a remarkable difference was found, i.e., that $V_{\max , \mathrm{s}}(\mathrm{JTWC})>V_{\max , \mathrm{s}}(\mathrm{CMA})>$ $V_{\text {max }, \mathrm{s}}(\mathrm{JMA})$ and $P_{\mathrm{c}}(\mathrm{JTWC})<P_{\mathrm{c}}(\mathrm{CMA})<P_{\mathrm{c}}(\mathrm{JMA})$ when TCs reach typhoon level, and this trend becomes apparent along with storm intensification (Song et al., 2010). It could be attributed to time interval differences since the JMA uses $10 \mathrm{~min}$ and the CMA uses $2 \mathrm{~min}$, while the JTWC uses $1 \mathrm{~min}$. The differences among estimation techniques and algorithms for determining $V_{\max , \mathrm{s}}$ and $P_{\mathrm{cs}}$ based on the Dvorak technique (Dvorak, 1984; Velden et al., 2006) with satellite cloud images could also contribute to this inconsistency. However, the 10 min time duration employed by the JMA is consistent with most design codes or standards and is also suggested by the WMO (Fang et al., 2019a). Furthermore, the 50-knot or 30 -knot radii information provided by the JMA dataset is a supplement of great importance in facilitating the estimation of TC wind field parameters. As a result, the JMA best-track dataset was selected as the basic information for the following TC hazards studies in the southeast China region.

\subsection{Statistical correlations}

In order to examine the statistical characteristics of historical track information around a site of interest, track segments that intersect and are within a circular subregion entered at the target location are usually extracted from the best-track dataset. The size of the subregion directly affects the data sampling as well as the final design wind speed prediction (Georgiou, 1985; Xiao et al., 2011; Li and Hong, 2015). A suitable circle size should enable the TC tracks and wind field parameters to be less sensitive and to cover as many high-wind-speed samples as possible. Three radii, 500,1000 and $250 \mathrm{~km}$, were employed by Vickery and Twisdale (1995), Xiao et al. (2011), and Li and Hong (2015), respectively. The use of $1000 \mathrm{~km}$ could overestimate the effects of high winds on a site of interest since some extremely violent typhoons over distant sea would be circled and used to model the central pressure before landfall. However, these typhoons have little chance of maintaining an extremely high intensity until landfall on mainland China. Based on the JMA dataset from 1951 to 2015, only seven violent typhoons ( $P_{\mathrm{cs}} \leq 935 \mathrm{hPa}$ or $V_{\mathrm{max}, \mathrm{s}} \geq 54 \mathrm{~m} \mathrm{~s}^{-1}, 105$ knots), 


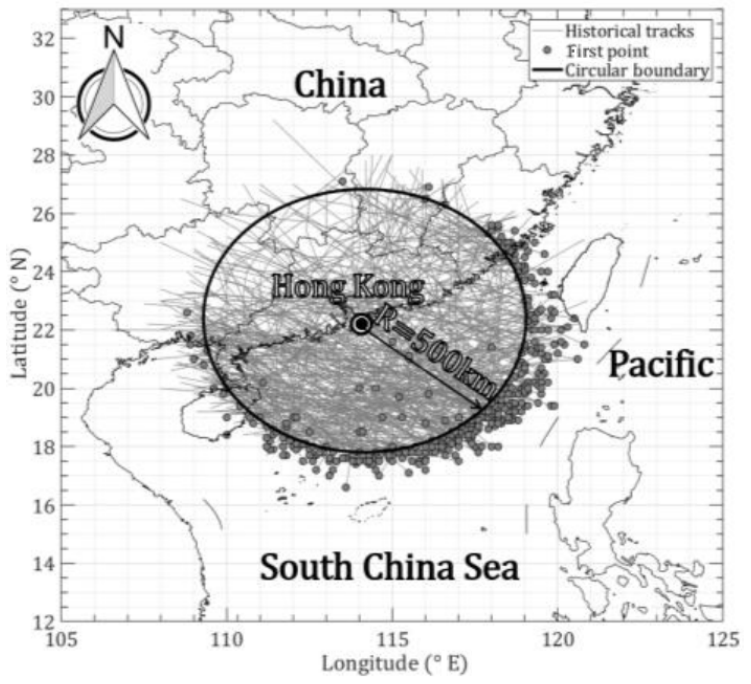

Figure 2. Track segments within a circular region centered on Hong Kong with a radius of $500 \mathrm{~km}$.

Nina (195307), Wanda (195606), Grace (195819), Saomai (200608), Hagupit (200814), Usagi (201319) and Rammasun (201409) directly landed on mainland China. Moreover, the largest $R_{\mathrm{max}, \mathrm{s} 0}$, illustrated in Figs. 8 and 16, range from 500 to $600 \mathrm{~km}$ if the size of subregion $R=500 \mathrm{~km}$ is employed. And as mentioned by Yuan et al. (2007), about $50 \%$ of the radii of historical storms associated with a wind speed of $15.4 \mathrm{~m} \mathrm{~s}^{-1}$ range from 222 to $463 \mathrm{~km}$ and only $10 \%$ are larger than $555 \mathrm{~km}$. In fact, we can show experimentally that at the outer regions of a typhoon, $500 \mathrm{~km}$ or more away from the storm center, there is only a slight influence on the specific region. Accordingly, $R=500 \mathrm{~km}$, which is consistent with Vickery and Twisdale (1995) and will be used in this study, allows as many high wind speeds as possible to be considered and avoids the overuse of some extremely violent typhoons.

Taking the example of the Hong Kong region (centered on $22.3186^{\circ} \mathrm{N}, 114.1678^{\circ} \mathrm{E}$ ), which is severely affected by TCs, 412 segments of track data within a circle of $R=$ $500 \mathrm{~km}$ were captured from the JMA dataset (1951-2015), as shown in Fig. 2. Although few TCs originate in this circular region, they only reach the strongest level of a severe tropical storm, with $P_{\mathrm{cs}}$ larger than $980 \mathrm{hPa}$ belonging to a normalintensity storm. Their genesis locations are also close to the circular boundary. Accordingly, all simulated tracks can be assumed to originate from the circular boundary by considering the location distribution of historical tracks in terms of origin angle $\alpha_{0}$, which is the direction relative to the site of interest and clockwise positive from the north.

The annual storm rate (storms per year) is usually modeled by negative binomial (Li and Hong, 2016) or Poisson (Xiao et al., 2011; Li and Hong, 2015) distributions. However, the mean of the storm genesis within the circular region around

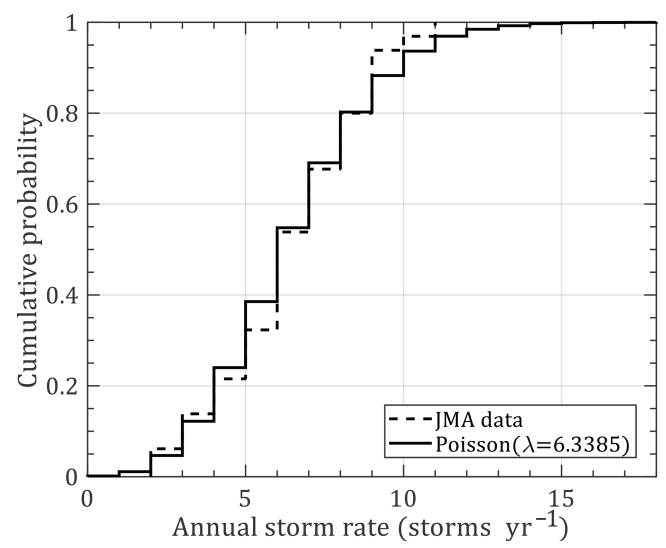

Figure 3. CDF of annual storm rate.

Hong Kong is 6.339, which is larger than the variance of 2.280. It does not satisfy the prerequisite of the negative binomial distribution. The Poisson distribution was employed to model the annual storm rate $\left(\lambda_{\mathrm{a}}\right)$, as shown in Fig. 3 . Based on the circular subregion method, the position of the first track dot $\left(\alpha_{0}\right)$ and its heading direction $\left(\theta_{\mathrm{T} 0}\right)$ determine the location of the simulated track line, while the translation speed $\left(V_{\mathrm{T} 0}\right)$ is used to estimate the TC center location at each time step. First values of the central pressure difference $\left(\Delta P_{0}\right)$ for each segment are applied for the TC intensity modeling before landfall. Based on the statistical characteristics of historical data, the probabilistic distributions of these four parameters are fitted with several commonly used models using a maximum likelihood method before achieving the most suitable choices by the K-S (Kolmogorov-Smirnov) distribution test. The preferable distribution models, i.e., Weibull, lognormal, bimodal normal and Burr type XII, for all genesis parameters and their probability density functions (PDFs) together with fitted coefficients are listed in Table 1. Correspondingly, Fig. 4 compares the observed and modeled cumulative distribution functions (CDFs) for these parameters. The critical value of the $\mathrm{K}-\mathrm{S}$ test for the historical data sample $(n=204)$ is 0.0952 at a $5 \%$ significance level larger than all the modeled results (values of $k$ in Fig. 4), which proves that we have enough evidence to simulate the virtual TC tracks by adopting these distribution models. It noteworthy that all observed $\Delta P$ and $\theta_{\mathrm{T}}$ values within the circle of interest are employed to model the distribution of $\Delta P_{0}$ and $\theta_{\mathrm{T} 0}$ due to the inherent drawback of the circular subregion method, which assumes for simplicity in the simulation that $\Delta P$ remains unchanged before the storm's landfall and $\theta_{\mathrm{T}}$ is a constant for each TC track. All information of $\Delta P$ and $\theta_{\mathrm{T}}$ can be taken into account to some extent when it is applied for modeling the distribution of $\Delta P_{0}$ and $\theta_{\mathrm{T} 0}$. 
Table 1. Distribution models and coefficients for TC track genesis parameters.

\begin{tabular}{|c|c|c|c|}
\hline Parameter & Model & Probability density function (PDF) & $\begin{array}{l}\text { Coefficient } \\
\text { (Hong Kong) }\end{array}$ \\
\hline$\lambda_{\mathrm{a}}$ & Poisson & $f(x ; \lambda)=\frac{\lambda^{x}}{x !} e^{-\lambda}, \quad x=0,1,2, \ldots, \infty$ & $\lambda=6.339$ \\
\hline$\alpha_{0}$ & Weibull & $f(x ; k, \gamma)=\frac{k}{\gamma}\left(\frac{x}{\gamma}\right)^{k-1} e^{-(x / \gamma)^{k}}, \quad x \geq 0$ & $\begin{array}{l}k=3.134 \\
\gamma=156.991\end{array}$ \\
\hline$\Delta P_{0}$ & Lognormal & $f(x ; \mu, \sigma)=\frac{1}{x \sigma \sqrt{2 \pi}} \exp \left\{\frac{-(\ln x-\mu)^{2}}{2 \sigma^{2}}\right\}, \quad x>0$ & $\begin{array}{l}\mu=3.062 \\
\sigma=0.576\end{array}$ \\
\hline$\theta_{\mathrm{T} 0}$ & $\begin{array}{l}\text { Bimodal } \\
\text { normal }\end{array}$ & $\begin{array}{l}f\left(x ; p, \mu_{1}, \sigma_{1}, \mu_{2}, \sigma_{2}\right)=p \frac{1}{\sigma_{1} \sqrt{2 \pi}} \exp \left\{\frac{-\left(x-\mu_{1}\right)^{2}}{2 \sigma_{1}^{2}}\right. \\
+(1-p) \frac{1}{\sigma_{2} \sqrt{2 \pi}} \exp \left\{\frac{-\left(x-\mu_{2}\right)^{2}}{2 \sigma_{2}^{2}}\right\}\end{array}$ & $\begin{array}{l}p=0.475 \\
\mu_{1}=-73.282 \\
\sigma_{1}=25.607 \\
\mu_{2}=0.002 \\
\sigma_{2}=68.030\end{array}$ \\
\hline$V_{\mathrm{T} 0}$ & $\begin{array}{l}\text { Burr type } \\
\text { XII }\end{array}$ & $\begin{array}{l}f(x ; \alpha, c, k)=\frac{\frac{k c}{\alpha}\left(\frac{x}{\alpha}\right)^{c-1}}{\left(1+\left(\frac{x}{a}\right)^{c}\right)^{k+1}} \\
x>0, \alpha>0, c>0, k>0\end{array}$ & $\begin{array}{l}\alpha=16.151 \\
c=2.540 \\
k=15.028\end{array}$ \\
\hline
\end{tabular}

Note that $x$ denotes the argument or the input of the function.
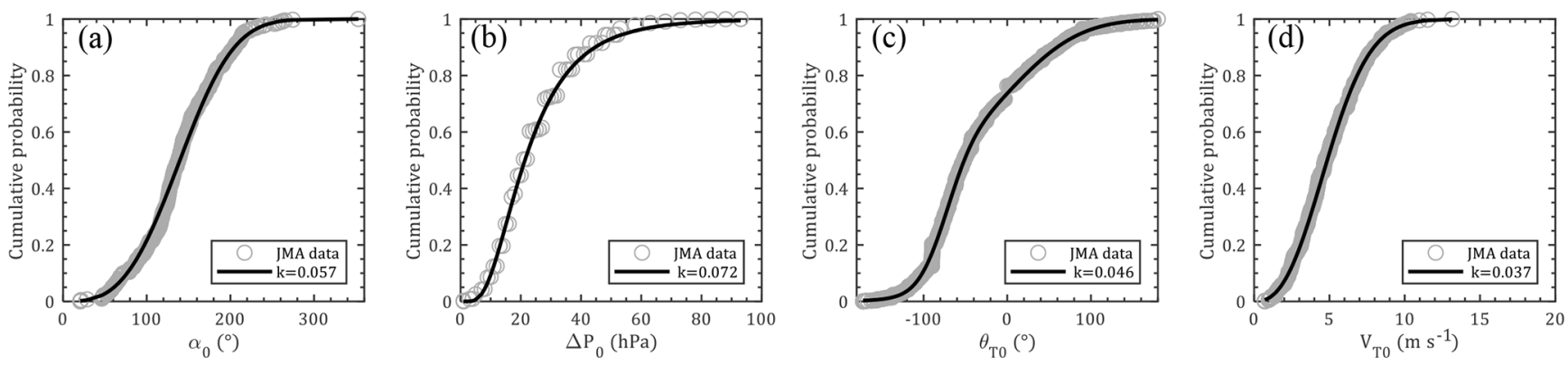

Figure 4. CDFs of track genesis parameters: (a) $\alpha_{0} ;$ (b) $\Delta P_{0} ;$ (c) $\theta_{\mathrm{T} 0} ;$ (d) $V_{\mathrm{T} 0}$.

\subsection{Translation speed}

The translation speed is used for determining the TC eye locations at every time step and contributes slightly to the TC wind speed field. Traditionally, it was randomly sampled from a historical data-based probability distribution (Xiao et al., 2011; Li and Hong, 2015). In reality, the translation speed of the next step should be correlated with previous steps, which is also the statistical basis for empirical full-track modeling (Vickery et al., 2000b; Li and Hong, 2016). As the real data (historical observations) illustrate in Fig. 6a-c, the TC translation speed in the Hong Kong region is strongly dependent on the previous two steps with correlation coefficients of 0.7729 and 0.6281 , while a weak correlation is observed with the heading angles. Accordingly, given the initial storm forward speed, the new speed for next steps can be modeled as a recursive formula

$$
\begin{aligned}
\ln V_{\mathrm{T}}(i+1) & =v_{1}+v_{2} \cdot \ln V_{\mathrm{T}}(i)+v_{3} \cdot \ln V_{\mathrm{T}}(i-1) \\
& +v_{4} \cdot \theta_{\mathrm{T}}(i+1)+\varepsilon_{\ln V_{\mathrm{T}}},
\end{aligned}
$$

in which $v_{j}(j=1-4)$ are model coefficients obtained from the least-squares regression analysis for historical data, $V_{\mathrm{T}}(i)$ is the translation speed at time step $i$, and $\varepsilon_{\ln V_{T}}$ is the error term accounting for modeling differences between the regression models and the real observations.

Based on the JMA dataset, the values of $v_{j}(j=1-4)$ are extracted as $0.3089,0.6338,0.1504$ and 0.0001 for the circular Hong Kong region. Model errors, as illustrated in Fig. 5a, are randomly distributed with a mean and standard deviation of 0 and 0.38 , respectively, which indicates that the model is unbiased and has no obvious trend. These errors are then statistically fitted with two types of probability distribution models, i.e., normal distribution and $t$ location-scale distri- 

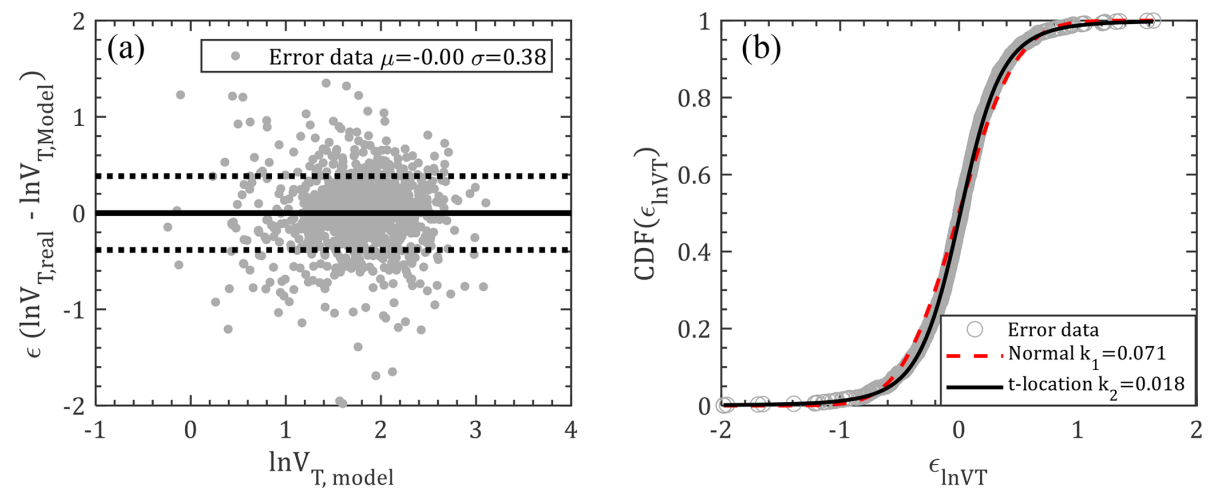

Figure 5. Logarithmic modeling errors for translation speed: (a) scatterplot; (b) CDF.
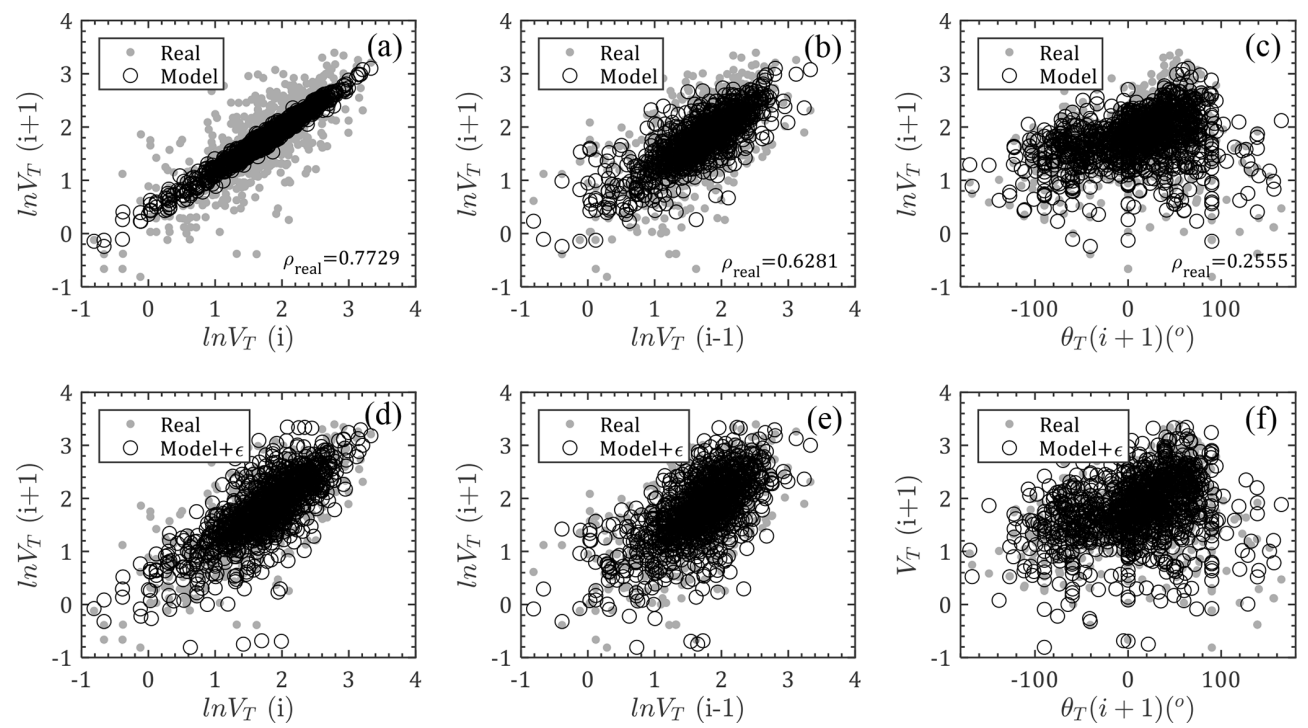

Figure 6. Comparison of translation speed between model and real observations: (a-c) relations between $\ln V_{\mathrm{T}}(i), \ln V_{\mathrm{T}}(i-1), \theta(i+1)$ and $\ln V_{\mathrm{T}}(i+1)$ without errors; (d-f) relations between $\ln V_{\mathrm{T}}(i), \ln V_{\mathrm{T}}(i-1), \theta(i+1)$ and $\ln V_{\mathrm{T}}(i+1)$ with errors; $\left(\rho_{\text {real }}\right.$ is the correlation coefficient for real observation data).

bution, which are formulated by the PDFs as

$$
\begin{aligned}
& f(x ; \mu, \sigma)=\frac{1}{\sigma \sqrt{2 \pi}} \exp \left\{\frac{-(x-\mu)^{2}}{2 \sigma^{2}}\right\}, \\
& f(x ; \mu, \sigma, \nu)=\frac{\Gamma\left(\frac{v+1}{2}\right)}{\sigma \sqrt{\nu \pi} \Gamma\left(\frac{v}{2}\right)}\left[\frac{\nu+\left(\frac{x-\mu}{\sigma}\right)^{2}}{v}\right]^{-\frac{v+1}{2}},
\end{aligned}
$$

in which $\mu \sigma$ and $v$ are location, scale and shape parameters. $\Gamma(\cdot)$ is the gamma function. As shown in Fig. $5 b$, the normal and $t$ location-scale distributions are separately applied to fit the model errors using the maximum likelihood method. Although the fitting results for both distributions look good, the critical value of the $\mathrm{K}-\mathrm{S}$ test for the observation data sample $(n=1060)$ is 0.0418 at the $5 \%$ significance level, which is smaller than the $\mathrm{K}-\mathrm{S}$ value fitted by normal distribution $(\mu=0, \sigma=0.38)$ but larger than that fitted by $t$ location-scale distribution $(\mu=0.0105, \sigma=0.2686$, $v=3.5871)$. Consequently, $t$ location-scale distribution is the preferable distribution for this case and will be used for error sampling.

As shown in Fig. 6, the forward speeds for next steps are modeled by Eq. (1) by introducing the historical track information and compared with observations. The first row (Fig. 6a-c) only considers the mean terms of Eq. (1), which indicates that the forward speed significantly depends on the previous steps using the linearly concentrated modeled mean values. The modeled mean values are more scattered with variation in translation speeds than with the previous second step and heading directions, but they are still within the scatter range of historical data. The second row, i.e., Fig. 6d-f, introduces the error term $\left(\varepsilon_{\ln V_{\mathrm{T}}}\right)$ modeled by $t$ location-scale distribution (Eq. 3) as mentioned before, which shows good agreement with the JMA observations. That is, the transla- 
tion wind speeds can be well generated using the recursive model of Eq. (1).

\section{Wind field model}

\subsection{TC wind field solutions}

A height-resolving TC boundary layer model developed by Meng et al. (1995) and enhanced by Fang et al. (2018a) is adopted in this study. It is also used to extract two typical TC wind field parameters: radius of maximum wind speed $\left(R_{\mathrm{max}, \mathrm{s}}\right)$ and radial pressure profile shape parameter $\left(B_{\mathrm{S}}\right)$ at surface level. It is then used to estimate the TC wind speed. Like most parametric TC wind field models, the surface pressure distribution in the radial direction is always prescribed and formulated by the Holland (1980) model, which is empirically determined by the location parameter $\left(R_{\mathrm{max}, \mathrm{s}}\right)$ and the shape parameter $\left(B_{\mathrm{S}}\right)$ to solve the air pressure term in the Navier-Stokes equation. By extending the Holland pressure model in the vertical direction using the gas state equation, accounting for the effects of temperature and moisture, a height-resolving parametric TC pressure field model (Fang et al., 2018a) is developed as

$$
\begin{aligned}
P_{r z} & =\left\{P_{\mathrm{cs}}+\Delta P_{\mathrm{s}} \cdot \exp \left[-\left(\frac{R_{\mathrm{max}, \mathrm{s}}}{r}\right)^{B_{\mathrm{s}}}\right]\right\} \\
& \left(1-\frac{g k z}{R_{\mathrm{d}} \theta_{\mathrm{v}}}\right)^{\frac{1}{k}},
\end{aligned}
$$

in which subscripts $r, z$ and s denote values at radius $r$, height $z$ and surface (nominal height $10 \mathrm{~m}$ ), respectively. $P_{r z}=$ air pressure at height $z$ and radius $r$ from the TC's axis (hPa); $P_{\mathrm{cs}}=$ surface central pressure $(\mathrm{hPa}) ; \Delta P_{\mathrm{s}}=P_{\mathrm{ns}}-P_{\mathrm{cs}}$ is the central pressure difference $(\mathrm{hPa})$, where $P_{\mathrm{ns}}$ is the peripheral pressure (usually taken as the pressure associated with the outermost closed isobar, $1013 \mathrm{hPa}$ in this study); $g=$ $9.8 \mathrm{~N} \mathrm{~kg}^{-1}$ is gravitational acceleration; $R_{\mathrm{d}}=287 \mathrm{~J}(\mathrm{~kg} \mathrm{~K})^{-1}$ is the specific gas constant of dry air; $\theta_{\mathrm{v}}=$ virtual potential temperature (K), and $k=R / c_{p}$ is the ratio of the gas constant of moist air $(R)$ to specific heat at constant pressure $\left(c_{p}\right)$. After that, the wind speed in free atmospheric air can be readily solved. The wind field solutions in the TC boundary layer based on the linearization of Navier-Stokes equations can be expressed as the sum of gradient wind speed $\left(V_{\mathrm{g}}\right)$ and decay wind speeds $\left(u_{\mathrm{d}} v_{\mathrm{d}}\right)$ due to frictional effects. More details regarding the wind field solutions are available in Fang et al. (2018a), which are omitted herein for brevity. One improvement is that the mixing length for determining the eddy viscosity is no longer a linear equation with height, but an upper bound $l_{\infty}$ of one-third of the boundary layer depth is introduced as suggested by Apsley (1995). That is, the mixing length is modeled as

$l_{\mathrm{v}}=\left[\frac{1}{\kappa\left(z+z_{0}\right)}+\frac{1}{l_{\infty}}\right]^{-1}$, in which $z_{0}$ is the equivalent roughness length $(\mathrm{m})$ and $\kappa \approx$ 0.4 is the von Kármán constant.

\subsection{Wind field parameters}

Two typical parameters, $R_{\max , \mathrm{s}}$ and $B_{\mathrm{s}}$, are always predefined to model the surface pressure field before solving the wind speed. The JMA best-track dataset is a preferable option for TC hazard assessments in the western Pacific. Its wind speed information in terms of maximum sustained surface wind speed $\left(V_{\max , \mathrm{s}}\right)$ and 50 or 30-knot wind radii is of great help in extracting $R_{\max , \mathrm{s}}$ and $B_{\mathrm{s}}$. Although the JTWC also provides information on $V_{\mathrm{max}, \mathrm{s}}$ as well as the wind radii with respect to 34, 50 and 64 knots and radius of maximum winds, the time-averaging issue should be carefully taken into account. Moreover, this wind information in the JTWC dataset is only available from 2001, while JMA documents extend over a longer record from 1977, so they are more reliable for developing the parent distribution for use in a Monte Carlo simulation. Accordingly, $R_{\max , \mathrm{s}}$ and $B_{\mathrm{s}}$ used in this study were extracted from the JMA best-track dataset (from 1977 to present) by using 50- or 30-knot radii information as well as the maximum sustained surface wind speeds. These wind data are applied to the aforementioned wind speed model to derive optimal pairs of $R_{\mathrm{max}, \mathrm{s}}$ and $B_{\mathrm{s}}$ by minimizing errors between the model and observations. For example, in Fig. 7, three radial wind profiles modeled by the optimally fitted $R_{\max , \mathrm{s}}$ and $B_{\mathrm{S}}$ closely match the JMA observation winds. It is noteworthy that the fitted values of $B_{\mathrm{s}}$ are slightly higher than traditional results, i.e., Vickery et al. (2000b) and Vickery and Wadhera (2008), while those of $R_{\max , \mathrm{s}}$ are almost unchanged. This is mainly attributed to the use of surface wind data and an analytical wind field model in this study (Fang et al., 2018a, 2019b). To fit a specific real wind speed, a higher value of $B_{\mathrm{S}}$ is required due to the decrease in central pressure difference from the surface to gradient layer when compared to no consideration of height-resolving characteristics of pressure field. Moreover, the analytical boundary layer model disregards some nonlinear terms and neglects the nonaxisymmetric effects (Fang et al., 2018a); a larger $B_{\mathrm{s}}$ is usually fitted to compensate for the deficiency of the model.

Then, the values of $R_{\mathrm{max}, \mathrm{s} 0}$ and $B_{\mathrm{s} 0}$ associated with the track genesis are determined from their probability distributions considering correlations with other parameters. As shown in Fig. $8, R_{\max , \mathrm{s} 0}$ and $B_{\mathrm{s} 0}$ are modeled by lognormal $(\mu=4.822 ; \sigma=0.571)$ and Burr type XII $(\alpha=1.974$, $c=6.362, k=2.001)$ distributions, respectively. The critical value of the $\mathrm{K}-\mathrm{S}$ test $(n=161)$ at a $5 \%$ significance level, say 0.1059, is larger than the test statistics ( $k$ values in Fig. 8), which fails to reject the null hypothesis. The correlations of $R_{\max , \mathrm{s} 0}$ and $B_{\mathrm{s} 0}$ with other parameters are also introduced and discussed in the next section.

By using the fitted results from the JMA dataset, the autocorrelations of $R_{\max , \mathrm{s}}$ as well as $B_{\mathrm{S}}$ between different time steps are simply taken into account using the recursive mod- 

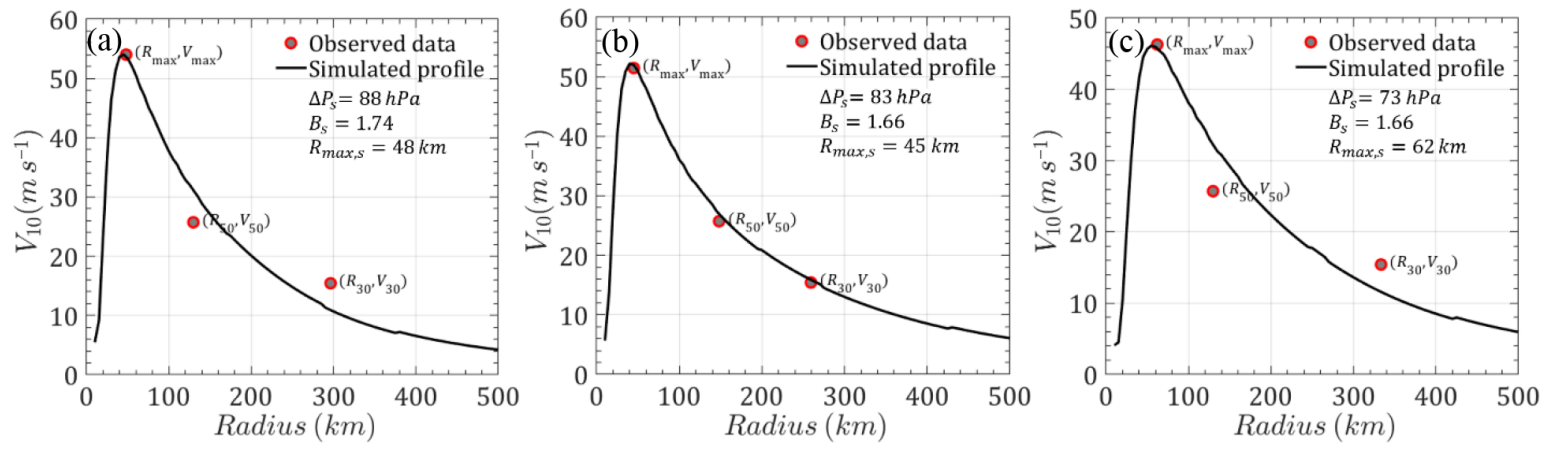

Figure 7. Radial wind speed profiles (a) Saomai (9 August 2006, 15:00 UTC), (b) Parma (1 October 2009, 06:00 UTC) and (c) Rammasun (18 July 2014, 12:00 UTC).
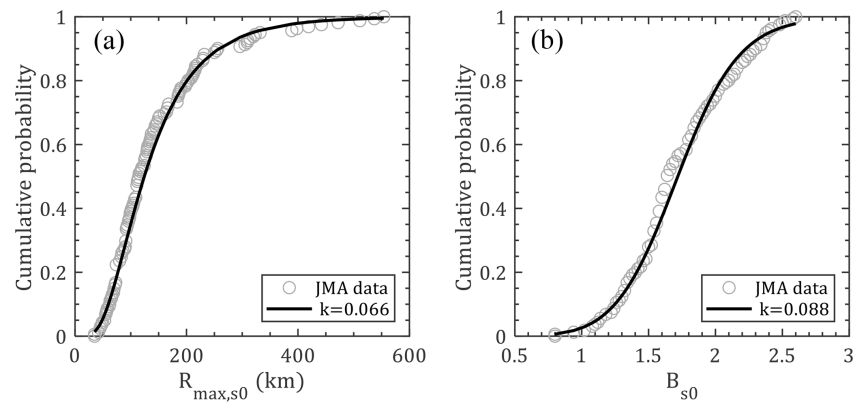

Figure 8. CDFs of wind field parameters at first step: (a) $R_{\max , \mathrm{s} 0}$; (b) $B_{\mathrm{s} 0}$.

els as

$$
\begin{aligned}
\ln R_{\max , \mathrm{s}}(i+1) & =r_{1}+r_{2} \cdot \ln R_{\max , \mathrm{s}}(i) \\
& +r_{3} \cdot \ln R_{\max , \mathrm{s}}(i-1)+r_{4} \cdot \Delta P_{\mathrm{S}}(i+1) \\
& +\varepsilon_{\ln R_{\max , \mathrm{s}},} \\
B_{\mathrm{S}}(i+1)= & b_{1}+b_{2} \cdot B_{\mathrm{S}}(i)+b_{3} \cdot B_{\mathrm{S}}(i-1) \\
& +b_{4} \cdot \ln R_{\max , \mathrm{s}}(i+1)+b_{5} \cdot \Delta P_{\mathrm{s}}(i+1) \\
& +\varepsilon_{B_{\mathrm{s}}},
\end{aligned}
$$

in which $r_{j}(j=1-4)$ and $b_{j}(j=1-5)$ are model coefficients that can be fitted with the least-squares regression method, $\ln R_{\max , \mathrm{s}}(i)$ and $B_{\mathrm{S}}(i)$ are values at time step $i$, and $\varepsilon_{\ln R_{\max }}$ and $\varepsilon_{B_{\mathrm{S}}}$ are error terms accounting for modeling differences between the models and observations. Using the data within the Hong Kong region from 1977 to 2015, the values of $r_{j}(j=1-4)$ and $b_{j}(j=1-5)$ are extracted as $0.7039,0.8341,0.0282$ and -0.0016 and $-0.6647,0.5432$, $-0.0112,0.2950$ and 0.0013 . As illustrated in Fig. 9a and $\mathrm{c}$, there is no obvious bias or potential trend for the error terms of $\ln R_{\max , \mathrm{s}}$ and $B_{\mathrm{S}}$ with a mean $(\mu)$ and standard deviation $(\sigma)$ of 0 and 0 and 0.29 and 0.20 , respectively. Like the translation speed modeled in Sect. 2.3, the error terms of $\ln R_{\mathrm{max}, \mathrm{s}}$ and $B_{\mathrm{s}}$ are both fitted with normal and $t$ locationscale distributions (Fig. 9b, d). It can be noted that both distributions are good candidates for reconstructing the errors, but $t$ location-scale distribution performs better with smaller $\mathrm{K}-\mathrm{S}$ values $\left(0.029\right.$ and 0.028 for $\varepsilon_{\ln R_{\text {max }, \mathrm{S}}}$ and $\left.\varepsilon_{B_{\mathrm{s}}}\right)$, while the critical value of the $\mathrm{K}-\mathrm{S}$ test for the observation data sample $(n=799)$ is 0.0478 at a $5 \%$ significance level. The fitted parameters for $\varepsilon_{\ln R_{\text {max }, \mathrm{s}}}$ and $\varepsilon_{B_{\mathrm{S}}}$ with $t$ location-scale distribution are $\mu=0.0107, \sigma=0.1470$ and $\nu=2.0340$ and $\mu=0.0054, \sigma=0.1461$ and $\nu=4.1558$, respectively.

As shown in Figs. 10-11, $R_{\mathrm{max}, \mathrm{s} 0}$ and $B_{\mathrm{s} 0}$ modeled by Eqs. (6) and (7) using the JMA historical data for previous steps are also compared with real observations for next steps. Similarly, the first rows in these two figures ignore the error terms, which are taken into account in the second rows. The values of previous first steps are observed to dominate the model results with linearly concentrated predictions, while previous second steps and other parameters have weaker effects with more scattered model values. After introducing the error terms, model values are able to successfully capture the historical data.

\subsection{Decay model}

Once the storm makes landfall, the central pressure deficit will witness a sudden decrease due to the cutoff of warm and moist air from the underlying oceanic environment, after which the TC intensity decay model or filling-rate model is adopted. The modeling of storm decay is of great importance for accurately estimating the TC design wind speed at the site of interest since the maximum winds normally occur during storm landfall in most cases. Georgiou (1985) modeled the decay of central pressure as a function of distance after landfall for four regions of the United States based on historical data. The other commonly used filling-rate model (Vickery, 2005) assumes that the central pressure deficit decays exponentially with time after landfall in the form of

$\Delta P(t)=\Delta P_{0} \cdot \exp (-a t)$

in which $t$ is the time after landfall (hour), $\Delta P_{0}$ is the central pressure difference at landfall (hPa), and $a$ is called the decay 

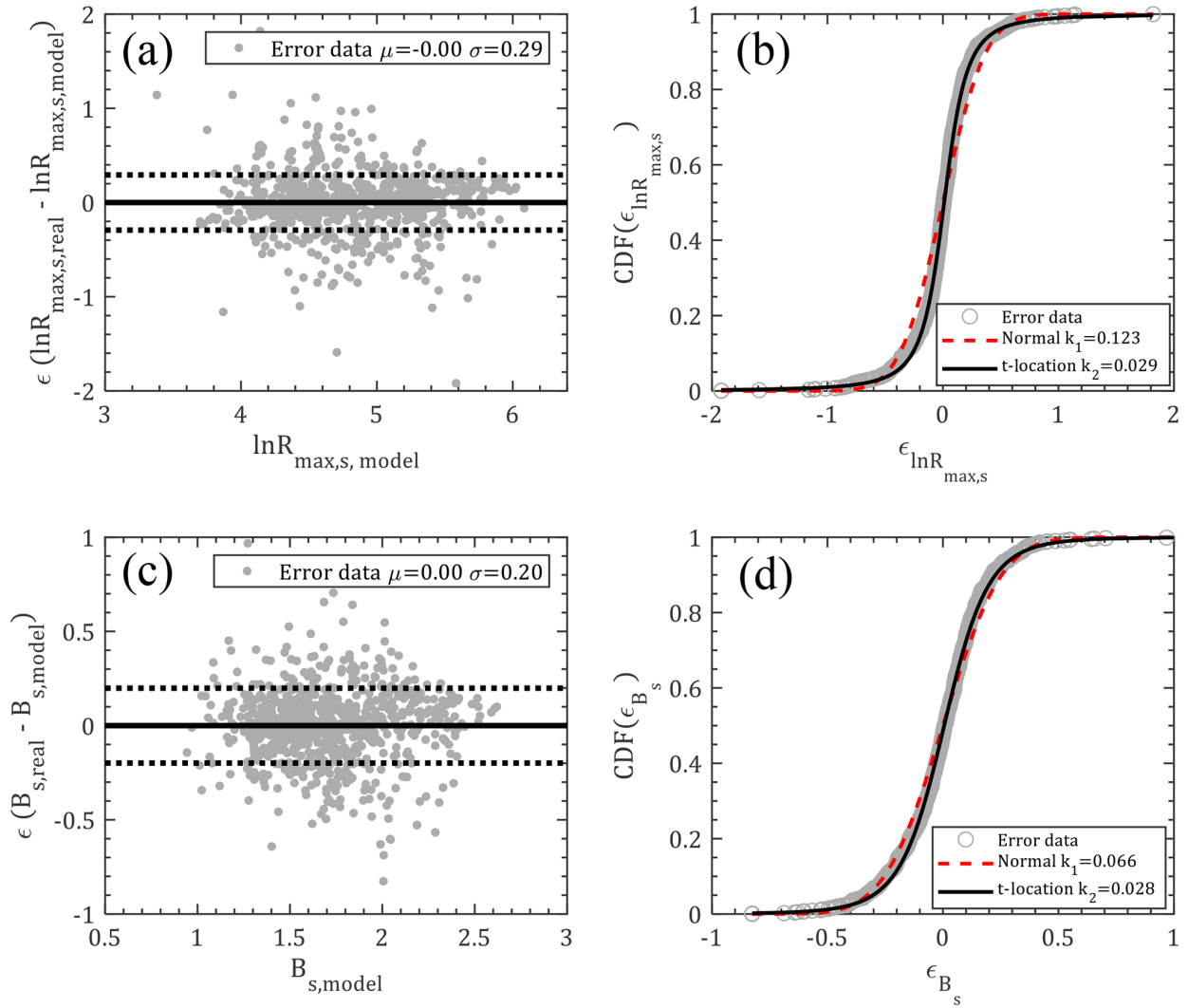

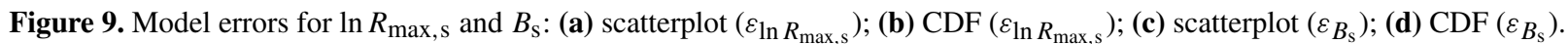
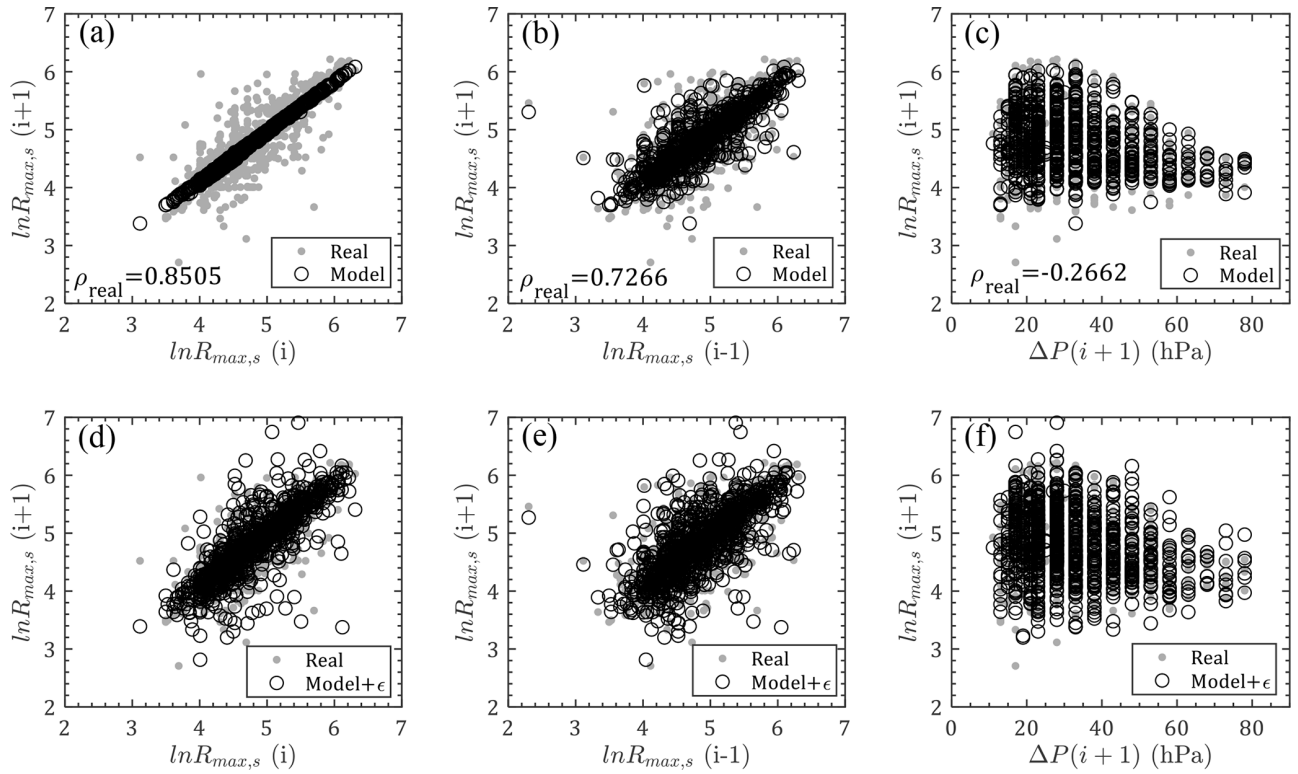

Figure 10. Comparison of $\ln R_{\max , \mathrm{s}}$ between model and real observations: (a-c) relations between $\ln R_{\max , \mathrm{s}}(i), \ln R_{\max , \mathrm{s}}(i-1), \Delta P(i+1)$ and $\ln R_{\max , \mathrm{s}}(i+1)$ without errors; (d-f) relations between $\ln R_{\max , \mathrm{s}}(i), \ln R_{\max , \mathrm{s}}(i-1), \Delta P(i+1)$ and $\ln R_{\max , \mathrm{s}}(i+1)$ with errors $\left(\rho_{\text {real }}\right.$ is the correlation coefficient for real observation data). 

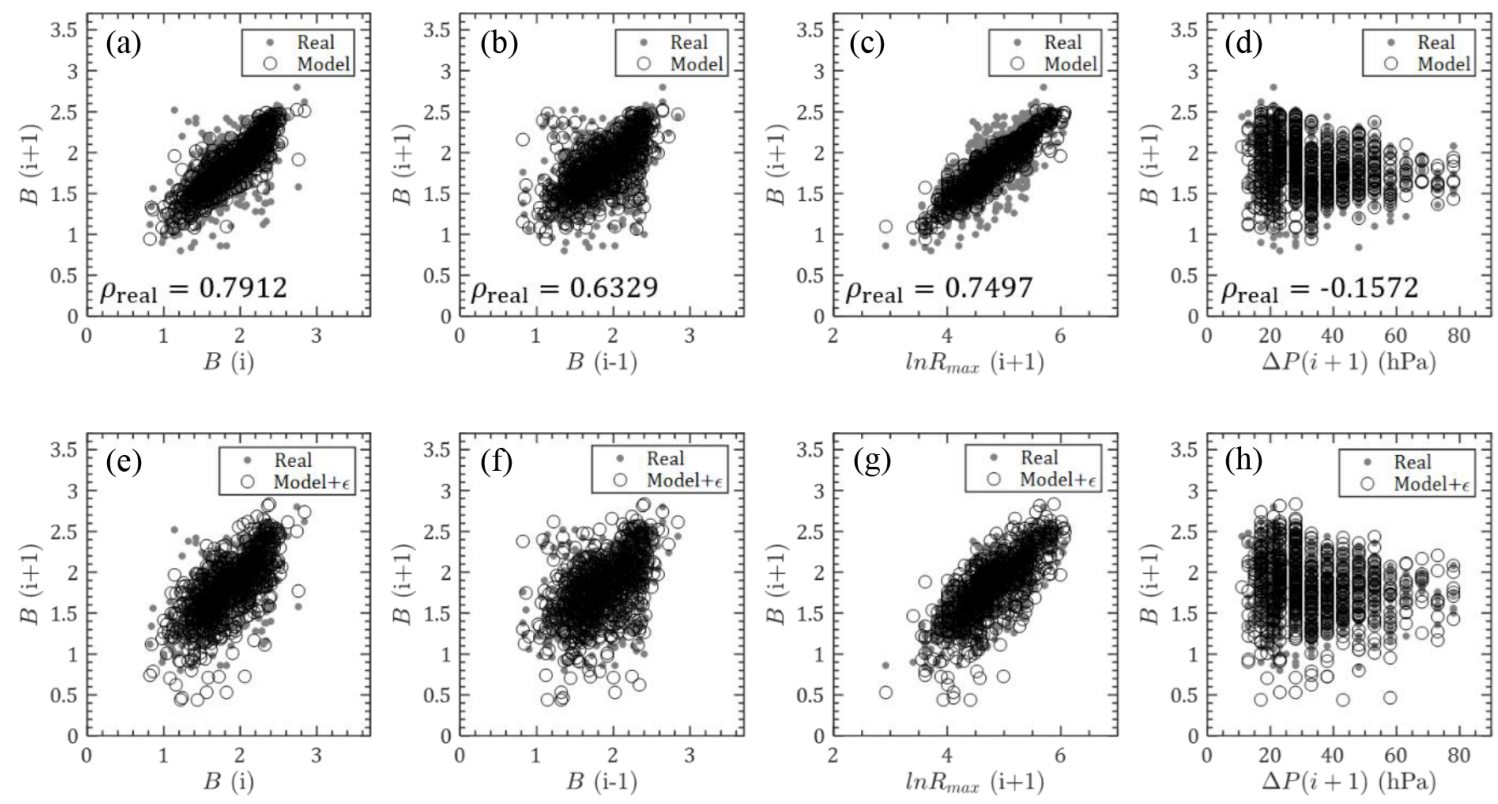

Figure 11. Comparison of $\mathbf{B}_{\mathrm{s}}$ between model and real observations: (a-d) relations between $B_{\mathrm{S}}(i), B_{\mathrm{S}}(i-1), \ln R_{\max , \mathrm{s}}(i+1), \Delta P(i+1)$ and $B_{\mathrm{S}}(i+1)$ without errors; (e-h) relations between $B_{\mathrm{S}}(i), B_{\mathrm{S}}(i-1), \ln R_{\max , \mathrm{s}}(i+1), \Delta P(i+1)$ and $B_{\mathrm{S}}(i+1)$ with errors $\left(\rho_{\text {real }}\right.$ is the correlation coefficient for real observation data).

rate, which is correlated with $\Delta P_{0}$ and modeled as

$a=a_{1}+a_{2} \Delta P_{0}+\varepsilon_{a}$,

where $a_{1}$ and $a_{2}$ are two region- and topographic-dependent coefficients, and $\varepsilon_{a}$ is a zero-mean normally distributed error term. As shown in Fig. 12a, the decay information of the ratio of central pressure deficit was extracted from the landfall TCs in the circular region around Hong Kong (Fig. 2) and fitted with the decay model of Eq. (8) using a leastsquares analysis. Generally, the decay model is well behaved although it is unable to capture the unchanged central pressures with time after landfall. This is also discussed in detail by Vickery (2005). Furthermore, the correlation between decay rate and central pressure difference at landfall is plotted in Fig. 12b with the correlation coefficient $\rho=0.3019$, which is also modeled by the linear function of Eq. (9). Then the residual error is unbiased and can be modeled by a normal distribution with a mean and standard deviation of 0 and 0.0227 , respectively.

\section{$4 \quad$ TC design wind speed prediction}

\subsection{Parameter correlations}

As shown by the scatterplots in Fig. 13, the observed (red triangles) genesis (at first time step) parameters show some correlations, especially between $\theta_{0}$ and $\alpha_{0}$ and between $R_{\max , \mathrm{s} 0}$ and $B_{\mathrm{s} 0}$ with correlation coefficients larger than 0.5. This means that the heading direction at the first time step is dependent on genesis location and two wind field parameters are strongly correlated with each other. Accordingly, the correlations between these genesis parameters, i.e., $\alpha_{0}, \Delta P_{0}, \theta_{0}$, $V_{\mathrm{T} 0}, R_{\mathrm{max}, \mathrm{s} 0}$ and $B_{\mathrm{s} 0}$, should be considered when utilizing the Cholesky decomposition method, which is a distributionfree approach introduced by Iman and Conover (1982). The randomly generated independent variables can be written into a matrix of size $N \times 6$ ( $N$ is the number of simulation samples) as

$\mathbf{X}=\left[\alpha_{0}, \Delta P_{0}, \theta_{0}, V_{\mathrm{T} 0}, R_{\max , \mathrm{s} 0}, B_{\mathrm{s} 0}\right]$.

The correlation coefficients of real data are assembled into a positive definite and symmetric matrix of $\mathbf{C}$. It can be alternatively expressed as $\mathbf{C}=\mathbf{A} \mathbf{A}^{\mathrm{T}}$ using the Cholesky decomposition method, in which $\mathbf{A}$ is a lower triangular matrix. If the correlation matrix of $\mathbf{X}$ is $\mathbf{Q}$, it can also be decomposed into the product of a lower triangular matrix $\mathbf{P}$ and its transpose $\mathbf{P}^{\mathrm{T}}$; i.e., $\mathbf{Q}=\mathbf{P P}^{\mathrm{T}}$. A matrix $\mathbf{S}=\mathbf{A} \mathbf{P}^{-1}$ can be determined such that $\mathbf{S Q S}^{\mathrm{T}}=\mathbf{C}$. After that, the final transformed correlated matrix $\mathbf{X}_{\mathrm{c}}=\mathbf{X \mathbf { S } ^ { \mathrm { T } }}$ can be obtained, which has the desired correlation matrix $\mathbf{C}$. It is noteworthy that the values in each column of the input $N \times 6$ matrix $\mathbf{X}$ can be rearranged to have the same rank order as the target matrix.

The correlated genesis samples for 100 years for Hong Kong are generated by Monte Carlo simulations coupled with parameter correlation analysis, as shown in Fig. 13. As can been seen, the observed JMA data points are scattered around the simulated results. And the correlation coefficients of the simulated variables $\left(\rho_{\text {sim }}\right)$ are almost identical to those of the original observations $\left(\rho_{\mathrm{obs}}\right)$. It is worth mentioning that the historical data for $\alpha_{0}, \Delta P_{0}, \theta_{0}$ and $V_{\mathrm{T} 0}$ are more than 

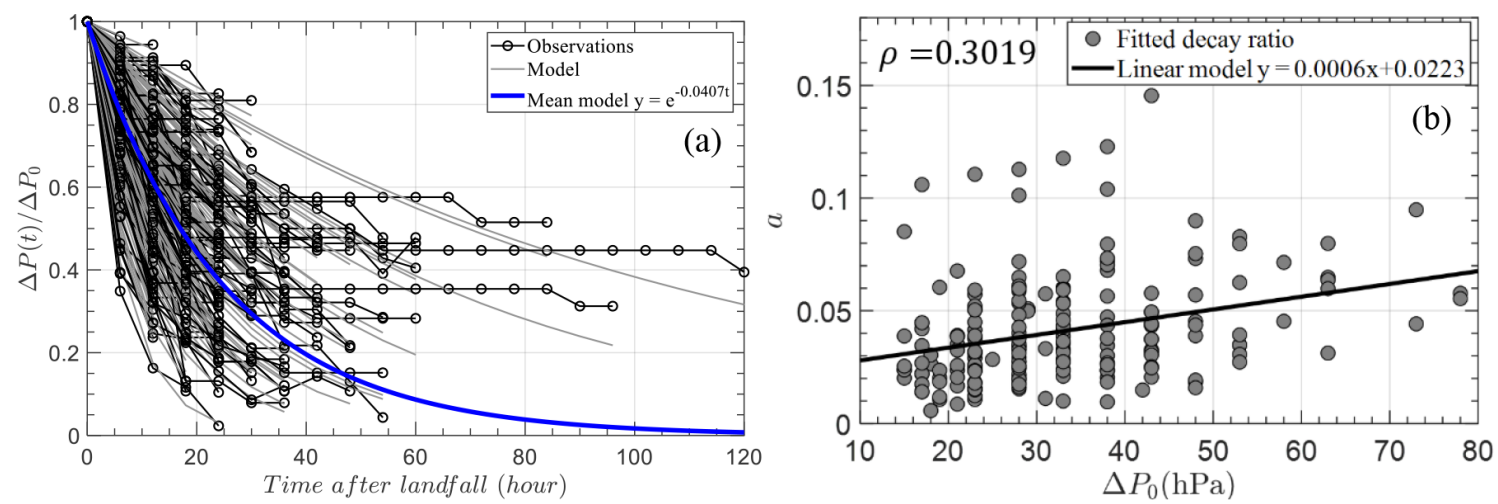

Figure 12. Decay model in circular subregion around Hong Kong: (a) curve fitting of decay model; (b) decay rate versus $\Delta P_{0}$.

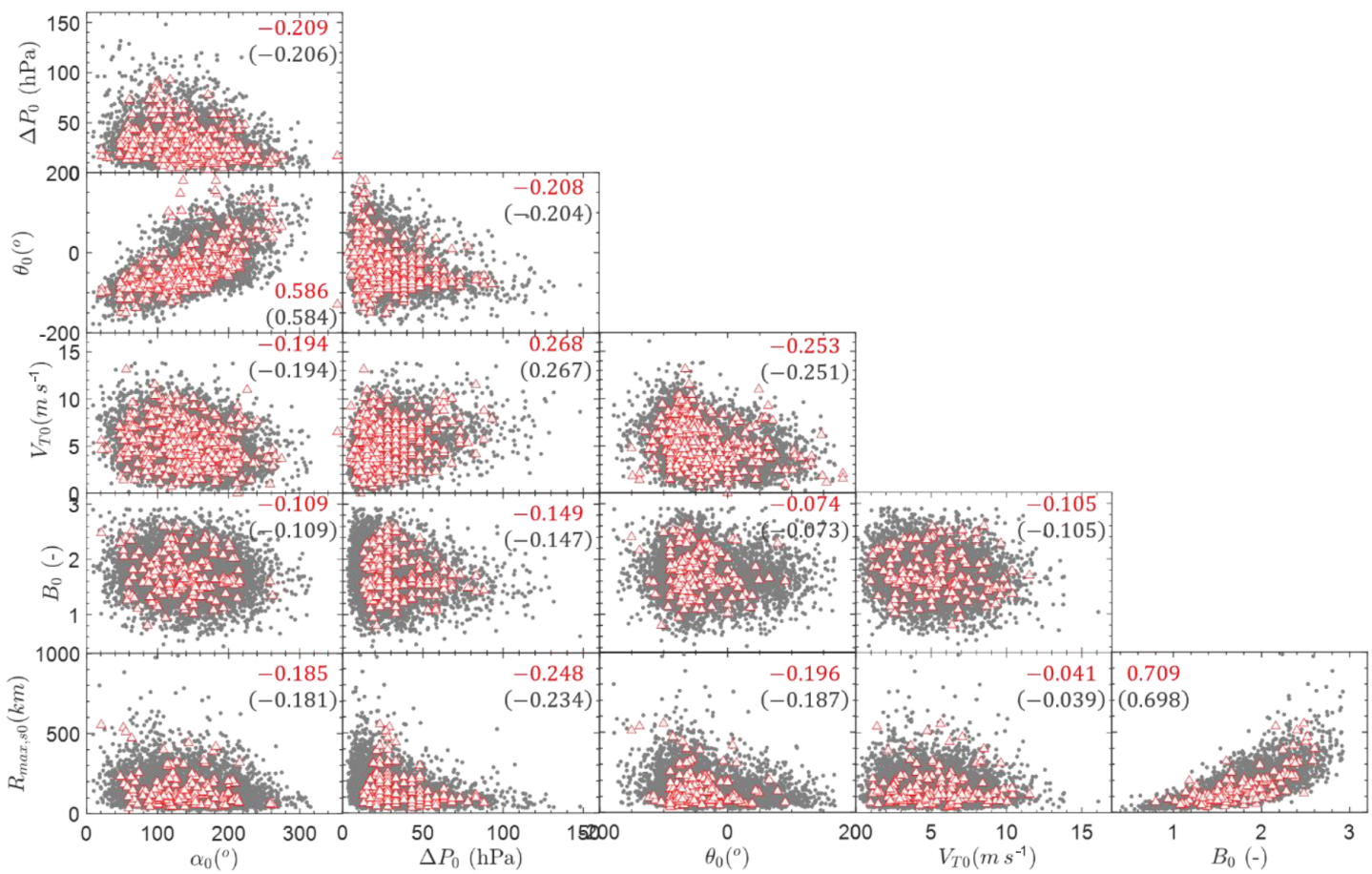

Figure 13. Simulated and observed genesis parameters (red triangles: observations; grey dots: simulations; upper numbers: $\rho_{\text {sim; }}$ lower numbers in parentheses: $\left.\rho_{\text {obs }}\right)$.

those for $R_{\mathrm{max}, \mathrm{s} 0}$ and $B_{\mathrm{s} 0}$ since the wind speed information is only available from 1977 and the wind data estimations are usually not provided during the first and last several time steps of a TC track due to its weak intensity. As a result, the scatterplots for historical observations in Fig. 13 associated with $R_{\max , \mathrm{s} 0}$ and $B_{\mathrm{s} 0}$ contain fewer data than others. Correspondingly, the correlation coefficients associated with these two parameters would also be derived from fewer data.

\subsection{Design wind speed prediction}

After generating the virtual tracks as well as the wind field parameters, the TC wind speed at the site of interest can be readily solved using the wind speed field model. Then, our final objective is to investigate the design wind speeds with various return intervals or TC wind hazard curves for the site of interest. For each site, 10000 -year simulations should be conducted to achieve adequate TC samples. The underlying terrain exposure is assumed to be consistent with the standard condition specified by the Load Code for the Design of Building Structures (GB-50009 2012; China National Standard, 2012), i.e., flat, open and low-density residential area of terrain category B with equivalent roughness length $z_{0}=0.05 \mathrm{~m}$. These simulated tracks can also be employed to estimate the wind speed with respect to other underlying exposures by simply using a desired input of $z_{0}$. And all sim- 
ulated tracks can be interpolated into $15 \mathrm{~min}$ so as to capture every potential maximum wind speed.

By assuming that the number of TCs occurring in a given season is independent of any other season, the occurrence probability $P_{\mathrm{T}}(n)$ of $n$ TCs over the time period $T$ can be assumed to follow the Poisson distribution. Then, the probability that the extreme wind speed $v_{i}$ is larger than a certain wind speed $V$ within a time period $T$ can be determined as

$$
\begin{aligned}
P_{\mathrm{T}}\left(v_{i}>V\right) & =1-\sum_{n=0}^{\infty} P\left(v_{i} \leq V \mid n\right) P_{\mathrm{T}}(n) \\
& =1-\exp \left(-\frac{N}{Y} T\right)
\end{aligned}
$$

in which $P\left(v_{i} \leq V \mid n\right)$ is the probability that the peak wind speed $v_{i}$ of a given TC is less than or equal to $V, N$ is the total number of TCs of which each has a peak wind $v_{i}$ larger than $V$, and $Y$ is total simulation years. Defining $T=1$ year, the annual probability of exceeding a given wind speed $V$ is

$$
\begin{aligned}
P_{\mathrm{T}} & =1 \text { year }\left(v_{i}>V\right)=1-\exp \left[-\lambda P\left(v_{i}>V\right)\right] \\
& =1-\exp \left(-\frac{N}{Y}\right)
\end{aligned}
$$

in which $\lambda$ is the annual storm occurrence rate within the region of interest. The mean recurrence interval (MRI) or return period (RP) of a given wind speed $V$ at a specific site can be estimated using the inverse of the result of Eq. (12) with the form

$\mathrm{RP}\left(v_{i}>V\right)=\frac{1}{\lambda P\left(v_{i}>V\right)}=\frac{Y}{N}$.

Figure 14 illustrates the empirical distribution of the annual maximum TC mean wind speeds $(10 \mathrm{~min}$ duration at $10 \mathrm{~m}$ height) curve as well as the return period curve of design mean wind speed in Hong Kong. Although the lognormal distribution is adopted for $\Delta P_{0}$ in this study, a similar distribution trend of annual maximum TC mean wind speed can be observed in this study and $\mathrm{Li}$ and Hong (2015) when $\Delta P$ is modeled by a Weibull distribution (Fig. 14a). A Weibull distribution was also preferred to the lognormal distribution in their study. However, the lognormal distribution is the preferred distribution in this study. This is mainly attributed to the use of different historical track datasets and a different subregion size. Li and Hong (2015) adopted the best-track dataset from the China Meteorological Agency and a radius of $250 \mathrm{~km}$ for the subregion circle. Thus, modeling the historical data with preferable probabilistic distributions is essentially important before the estimation of TC design wind speed can be regarded as a site-specific issue.

Moreover, Fig. 14b compares the predicted design mean wind speeds with the recommended values in Wind-resistant Design Specification for Highway Bridges (JTG/T D60-012004, code hereafter; China Trade Standard, 2004) for different return periods. It can be noted that the code's values are larger than those obtained in this study and the difference seems to decrease with an increase in return period. This is because the values recommended in the code are developed by statistical approaches based on both TC and non-TC observations over 30-40 years. Some strong non-TC winds captured by meteorological stations could dominate the design values for short return periods, while strong TC winds would control the higher design wind speed corresponding to longer return periods.

As mentioned in the explanatory materials to the Hong Kong Code (Buildings Department, 2004a, b), the 50-year MRI hourly mean wind speed of $46.9 \mathrm{~m} \mathrm{~s}^{-1}$ at $90 \mathrm{~m}$ above mean sea level with the underlying exposure of open sea was selected as the reference. In this case, the $10 \mathrm{~m}$ wind speed is estimated as $36.83 \mathrm{~m} \mathrm{~s}^{-1}$ using the power wind profile with the suggested exponent of 0.11 ( 0.12 for terrain exposure $\mathrm{A}$ in the Chinese code, $1 / 9$ for terrain exposure $\mathrm{D}$ in ASCE 7-16). The estimated $10 \mathrm{~min}$ mean wind speed is roughly $39.04 \mathrm{~m} \mathrm{~s}^{-1}$ if the conversion factor is 1.06 from $1 \mathrm{~h}$ to $10 \mathrm{~min}$. However, in order to be consistent with the reference exposure in this study $\left(z_{0}=0.05\right)$, the gradient wind speed can be determined as $56.64 \mathrm{~m} \mathrm{~s}^{-1}$ at $500 \mathrm{~m}$ and is assumed to be the same as other exposures. Then, the $10 \mathrm{~min}$ wind speed at a height of $10 \mathrm{~m}$ associated with open flat terrain can be calculated as $33.39 \mathrm{~m} \mathrm{~s}^{-1}$ if the power exponent is 0.15 ( 0.16 for terrain exposure B in the Chinese code, $1 / 6.5$ for terrain exposure C in ASCE 7-16) and the same gradient height is employed. This value is about $2 \mathrm{~m} \mathrm{~s}^{-1}$ smaller than the result of this study $\left(35.16 \mathrm{~m} \mathrm{~s}^{-1}\right)$. Similar results can be found from Kwok et al. (2006), who summarized that the over-sea wind speed at a height of $500 \mathrm{~m}$ with an MRI of 50 years was within the range of $54-57 \mathrm{~m} \mathrm{~s}^{-1}$ based on the historical TC records and recommended a slightly higher value of $59.5 \mathrm{~m} \mathrm{~s}^{-1}$ for design purposes. The corresponding 10 min mean wind speed associated with $z_{0}=0.05$ is estimated to be $35.07 \mathrm{~m} \mathrm{~s}^{-1}$ by following the same algorithm, which compares favorably to the result in the present study. Accordingly, the predicted design wind speed in Hong Kong in this study has an expected level of confidence for engineering applications.

\subsection{TC wind hazards at selected coastal cities in China}

For comparison with other studies (Xiao et al., 2011; Li and Hong, 2015), nine other coastal cities (Fig. 15), i.e., Shanghai, Ningbo, Wenzhou, Fuzhou, Xiamen, Guangzhou, Shenzhen, Zhanjiang and Haikou, were selected for Monte Carlo simulations following the aforementioned algorithm. Because the Burr distribution fails to fit the empirical $B_{\mathrm{s} 0}$ in Shanghai, Ningbo and Wenzhou, the generalized extreme value (GEV) distribution was employed to model $B_{\mathrm{s} 0}$ of these three cities. GEV distribution is a commonly used distribution developed from extreme value theory to combine the Gumbel, Fréchet and Weibull function families, also known as types I, II and III extreme value distributions. Its 

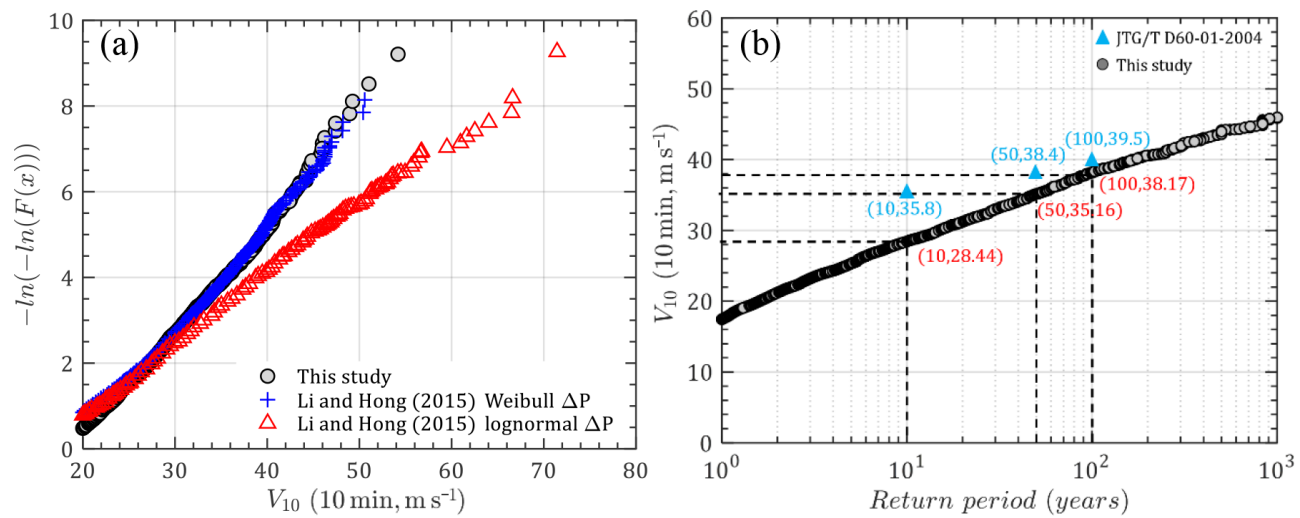

Figure 14. Design mean wind speed in Hong Kong: (a) empirical distribution; (b) mean wind speed versus return periods.

PDF can be expressed as

$$
\begin{aligned}
f(x ; \mu, \sigma, \gamma) & =\frac{1}{\sigma} \exp \left[-\left(1+\gamma \cdot \frac{x-\mu}{\sigma}\right)^{-\frac{1}{\gamma}}\right] \\
& \left(1+\gamma \cdot \frac{x-\mu}{\sigma}\right)^{-1-\frac{1}{\gamma}}, \quad \gamma \neq 0, \\
f(x ; \mu, \sigma, 0) & =\frac{1}{\sigma} \exp \left[-\exp \left(-\frac{x-\mu}{\sigma}\right)\right. \\
& \left.-\frac{x-\mu}{\sigma}\right], \quad \gamma=0,
\end{aligned}
$$

in which $\gamma, \sigma$ and $\mu$ are called shape, scale and location parameters, respectively, and $1+\gamma(x-\mu) / \sigma>0$. Correspondingly, for $\gamma=0, \gamma>0$ and $\gamma<0$ conditions, GEV distributions can be reduced to types I, II and III extreme value distributions. As shown in Tables 2-3, coefficients of each distribution for various input parameters in another nine coastal cities of China were estimated using a maximum likelihood method based on historical observation around the site of interest within a radius of $500 \mathrm{~km}$. The annual storm rate was observed to gradually increase from north to south. The fitted coefficients of recursive models of $V_{\mathrm{T}}, R_{\mathrm{max}, \mathrm{s}}$ and $B_{\mathrm{S}}$ as well as the decay model coefficients are also listed in Table 3. Correspondingly, the empirical and fitted preferred CDFs for each parameter in nine cities are illustrated in Fig. 16 together with the K-S test statistics. It can be seen that the distribution models successfully matched the empirical historical samples.

Like Hong Kong, the 10 min mean design wind speeds at a height of $10 \mathrm{~m}$ above the ground with a surface roughness of $0.05 \mathrm{~m}$ with respect to various return periods were developed based on 10000 -year Monte Carlo simulations. Table 4 lists the simulation results for TC design wind speed at selected cities with an MRI of 100 years and compares them with two Chinese codes (JTG/T D60-01-2004; GB 500092012) as well as other pioneering studies. The design wind speeds in the two codes are consistent with each other, ex-

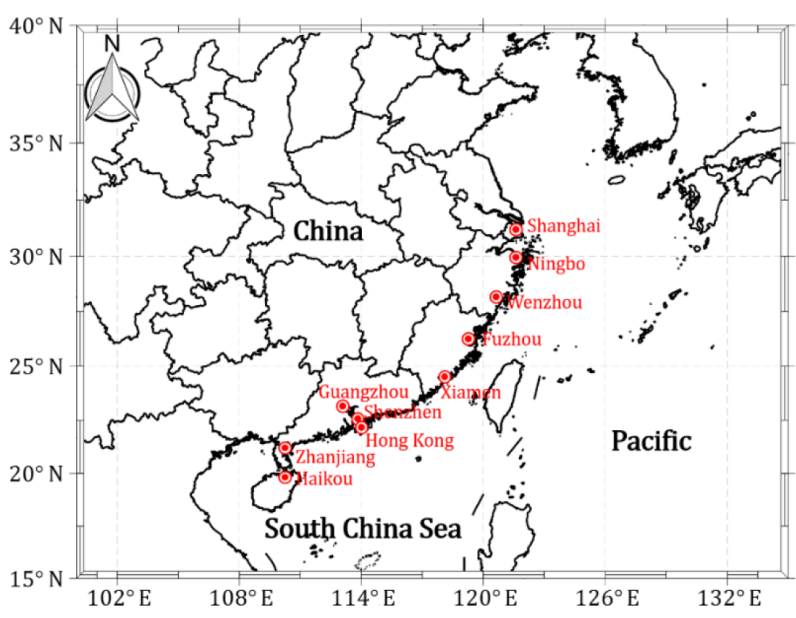

Figure 15. Locations of 10 selected coastal cities in China.

cept for a $2.5 \mathrm{~m} \mathrm{~s}^{-1}$ difference in Shanghai. It can be seen that the predicted wind speeds in this study are close to the code-recommended values, except for in Ningbo, Wenzhou, Zhanjiang and Haikou. The estimated values for Ningbo and Wenzhou are more than $4 \mathrm{~m} \mathrm{~s}^{-1}$ higher than those in the codes, while those for Zhanjiang and Haikou are more than about $4 \mathrm{~m} \mathrm{~s}^{-1}$ smaller. A similar trend can also be observed from the differences between $\mathrm{Li}$ and Hong (2016), Chen and Duan (2018), Wu and Huang (2019), and the codes. This is mainly attributed to the limitations of the statistically shortterm data-based method used in the code development. As mentioned before, the design wind speeds in the Chinese codes are developed from short-term observations utilizing both TC and non-TC winds (30-40 years). However, the series of largest annual wind speeds are, in most cases, not well behaved (Simiu and Scanlan, 1996) when used for modeling the probabilistic behavior of the extreme winds since most of the largest annual winds are remarkably smaller than the extreme winds associated with TCs. That is, the contribution of each group of data used for characterizing the probabilistic behavior of the largest annual winds is uneven, resulting 
Table 2. Coefficients of PDFs for TC track genesis parameters.

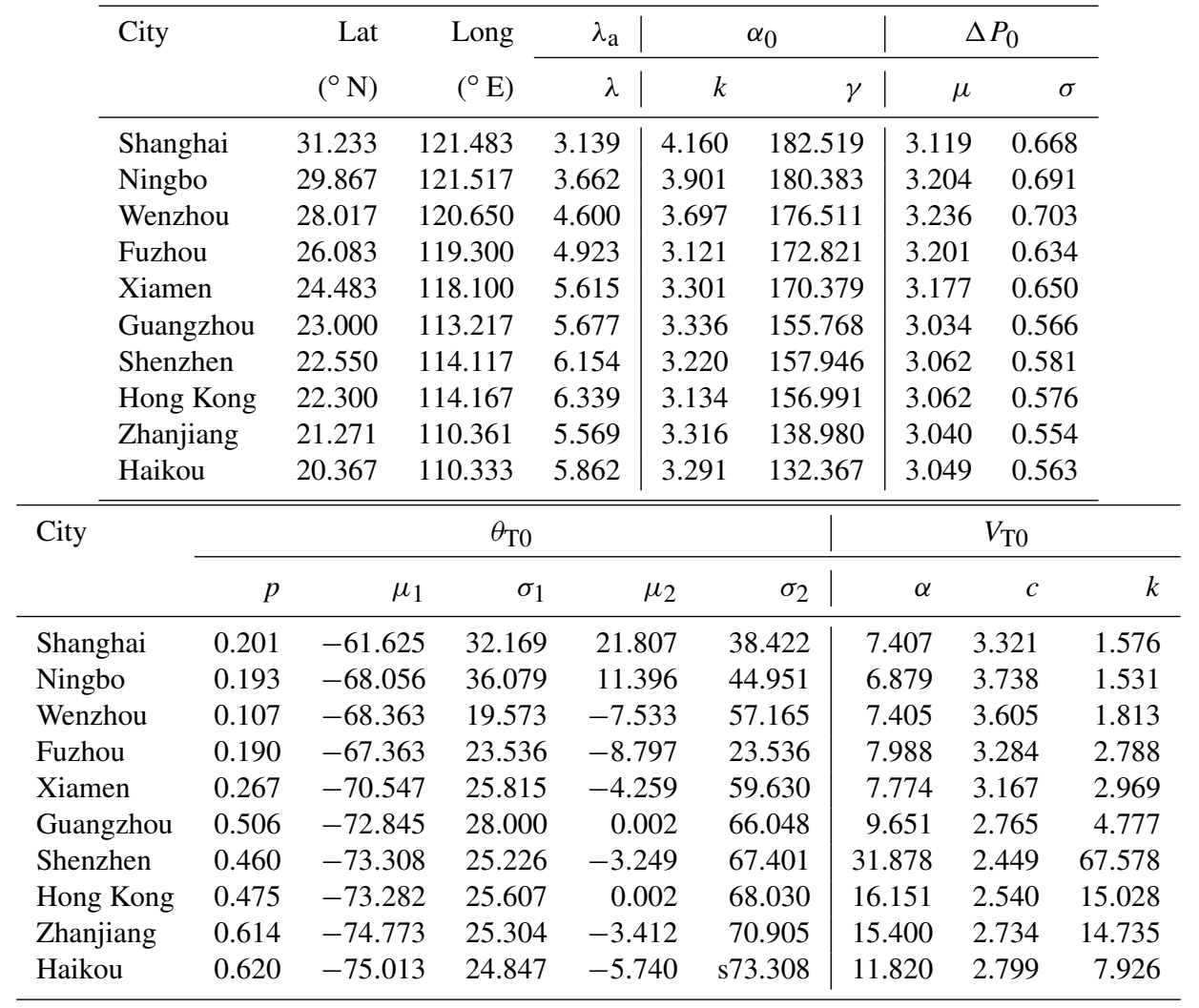

Table 3. Coefficients of PDFs and recursive models for wind field parameters.

\begin{tabular}{|c|c|c|c|c|c|c|c|c|c|c|c|c|c|c|c|c|}
\hline & \multirow{2}{*}{\multicolumn{2}{|c|}{ City }} & \multicolumn{6}{|c|}{$B_{\mathrm{s} 0}$} & \multicolumn{7}{|c|}{$V_{\mathrm{T}}$} & \\
\hline & & & $\mu$ & $\sigma$ & $\alpha(\mu)$ & $c(\sigma)$ & & (k) & & $v_{1}$ & & $v_{2}$ & $v_{3}$ & & $v_{4}$ & \\
\hline & \multicolumn{2}{|c|}{ Shanghai } & 5.062 & 0.665 & 1.850 & 0.501 & -0 & & 0.3 & 325 & 0.70 & & 0.129 & $1.283 \times$ & $10^{-3}$ & \\
\hline & \multicolumn{2}{|c|}{ Ningbo } & 5.064 & 0.640 & 1.839 & 0.479 & -0 & & 0.3 & 319 & 0.68 & & 0.147 & $1.273 \times$ & $10^{-3}$ & \\
\hline & \multicolumn{2}{|c|}{ Wenzhou } & 4.905 & 0.628 & 1.705 & 0.440 & -0 & & 0.2 & 273 & 0.64 & & 0.209 & $9.689 \times$ & $10^{-4}$ & \\
\hline & \multicolumn{2}{|c|}{ Fuzhou } & 4.831 & 0.567 & 2.055 & 6.439 & & & & 344 & 0.60 & & 0.201 & $8.444 \times$ & $10^{-4}$ & \\
\hline & \multicolumn{2}{|c|}{ Xiamen } & 4.805 & 0.591 & 1.850 & 7.198 & & & 0.3 & 358 & 0.59 & & 0.196 & $7.724 \times$ & $10^{-4}$ & \\
\hline & \multicolumn{2}{|c|}{ Guangzhou } & 4.802 & 0.598 & 1.779 & 6.895 & & & 0.3 & 305 & 0.61 & & 0.179 & $1.304 \times$ & $10^{-4}$ & \\
\hline & \multicolumn{2}{|c|}{ Shenzhen } & 4.817 & 0.631 & 2.610 & 5.154 & & 36 & & 303 & 0.63 & & 0.154 & $1.129 \times$ & $10^{-4}$ & \\
\hline & \multicolumn{2}{|c|}{ Hong Kong } & 4.822 & 0.571 & 1.974 & 6.362 & & & & 309 & 0.63 & & 0.150 & $1.094 \times$ & $10^{-4}$ & \\
\hline & \multicolumn{2}{|c|}{ Zhanjiang } & 4.830 & 0.571 & 1.545 & 8.526 & & & & 276 & 0.61 & & 0.181 & $-3.284 \times$ & $10^{-4}$ & \\
\hline & \multicolumn{2}{|c|}{ Haikou } & 4.813 & 0.575 & 1.529 & 9.024 & & & & 282 & 0.61 & & 0.179 & $-3.499 \times$ & $10^{-4}$ & \\
\hline \multirow[t]{2}{*}{ City } & \multicolumn{6}{|c|}{$R_{\max , \mathrm{s}}$} & \multicolumn{8}{|c|}{$B_{\mathrm{S}}$} & \multicolumn{2}{|r|}{$a$} \\
\hline & $r_{1}$ & $r_{2}$ & & $r_{3}$ & & $r_{4} \mid$ & $b_{1}$ & & $b_{2}$ & $b$ & $b_{3}$ & $b_{4}$ & & $b_{5}$ & $a_{1}$ & $a_{2}$ \\
\hline Shanghai & 0.544 & 0.866 & & 0.037 & $-1.172 \times 1$ & $0^{-3}$ & -1.104 & 0.3 & & 0.04 & & 0.449 & $-1.1^{\prime}$ & $72 \times 10^{-3}$ & 0.020 & $5.026 \times 10^{-4}$ \\
\hline Ningbo & 0.510 & 0.856 & & 0.056 & $-1.359 \times 1$ & $0^{-3}$ & -0.870 & 0.3 & & 0.04 & & 0.390 & -1.3 & $59 \times 10^{-3}$ & 0.014 & $6.083 \times 10^{-4}$ \\
\hline Wenzhou & 0.668 & 0.871 & & 0.018 & $-1.886 \times 1$ & $0^{-3}$ & -0.918 & 0.4 & & -0.02 & & 0.403 & 1.5 & $38 \times 10^{-3}$ & 0.024 & $4.430 \times 10^{-4}$ \\
\hline Fuzhou & 0.637 & 0.899 & $-2.888 \times$ & $10^{-3}$ & $-2.013 \times 1$ & $0^{-3}$ & -0.899 & 0.3 & & -0.02 & & 0.404 & 1.7 & $70 \times 10^{-3}$ & 0.024 & $4.242 \times 10^{-4}$ \\
\hline Xiamen & 0.657 & 0.910 & & 0.023 & $-1.592 \times 1$ & $0^{-3}$ & -0.804 & 0.4 & & -0.05 & & 0.374 & $1.1^{\circ}$ & $79 \times 10^{-3}$ & 0.024 & $4.787 \times 10^{-4}$ \\
\hline Guangzhou & 0.727 & 0.824 & & 0.032 & $-1.646 \times 1$ & $0^{-3}$ & -0.626 & 0.5 & & -0.02 & & 0.298 & 4.9 & $51 \times 10^{-4}$ & 0.022 & $5.801 \times 10^{-4}$ \\
\hline Shenzhen & 0.703 & 0.813 & & 0.039 & $-3.815 \times 1$ & $0^{-4}$ & -0.603 & 0.5 & & 0.00 & & 0.269 & 6.1 & $82 \times 10^{-4}$ & 0.026 & $5.201 \times 10^{-4}$ \\
\hline Hong Kong & 0.704 & 0.834 & & 0.028 & $-1.630 \times 1$ & $0^{-3}$ & -0.665 & 0.5 & & -0.01 & & 0.295 & 1.3 & $00 \times 10^{-3}$ & 0.022 & $5.654 \times 10^{-4}$ \\
\hline Zhanjiang & 0.703 & 0.813 & & 0.039 & $-3.815 \times 1$ & $0^{-4}$ & -0.603 & 0.5 & & 0.00 & & 0.269 & 6.1 & $82 \times 10^{-4}$ & 0.026 & $5.201 \times 10^{-4}$ \\
\hline Haikou & 0.680 & 0.803 & & 0.054 & $-4.531 \times 1$ & & -0.642 & 0.5 & & 0.01 & & 0.275 & 1.1 & $67 \times 10^{-3}$ & 0.028 & $5.184 \times 10^{-4}$ \\
\hline
\end{tabular}



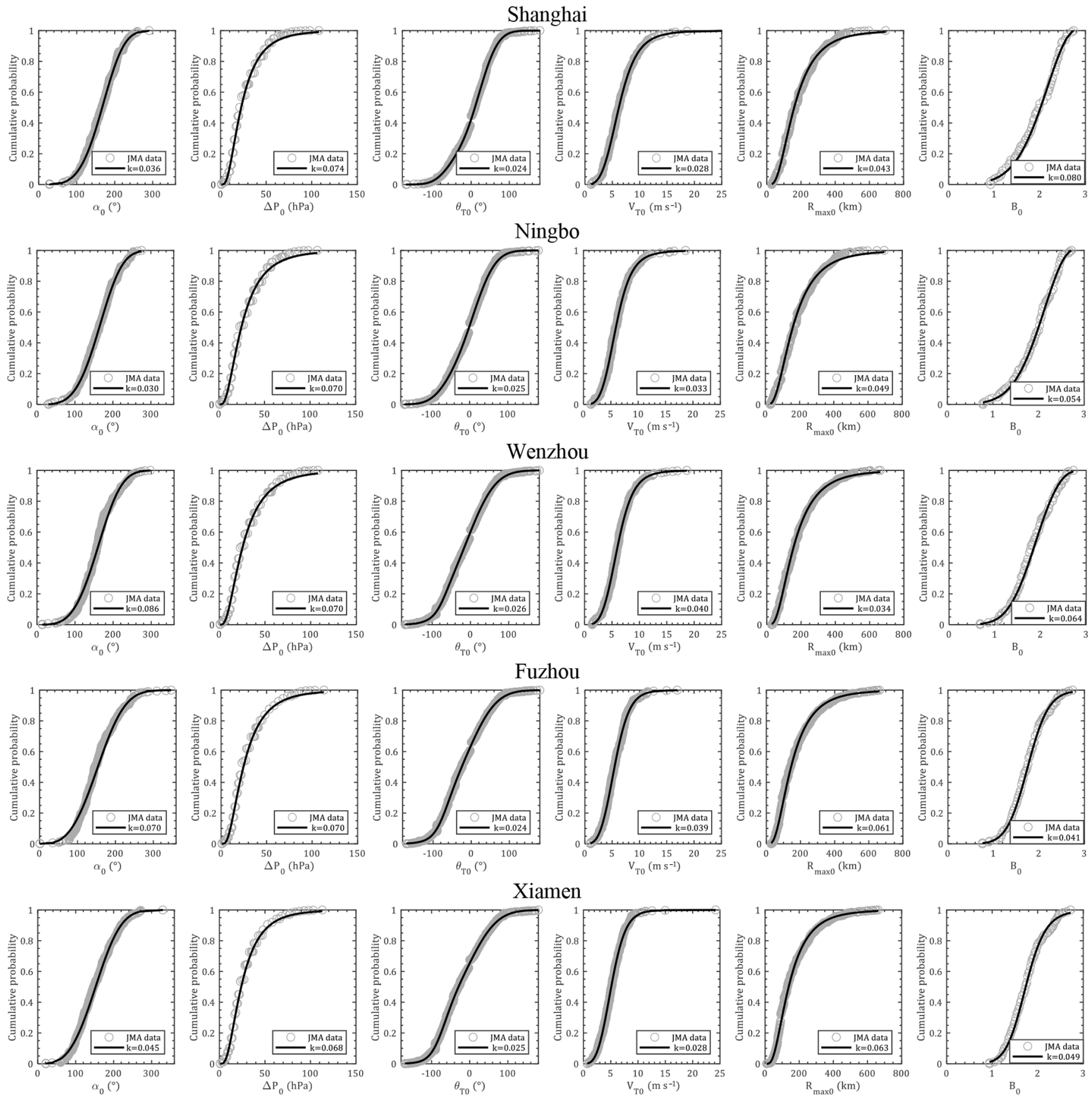

Figure 16.

in some unrealistically high or low predictions (Simiu and Scanlan, 1996). Although some alternative approaches can be adopted to better consider TC winds, such as the use of maximum average monthly speed or mixed distributions of TC and non-TC winds, to the authors' knowledge, no published literature clearly discusses the development of design wind speed in the Chinese codes. Furthermore, the correction of averaging time, height, station migration and surrounding roughness to make the wind speed records meteorologically homogeneous would introduce some unpredictable errors.

Moreover, as shown in Fig. 17, violent typhoons $\left(P_{\mathrm{cs}} \leq\right.$ $935 \mathrm{hPa}$ or $V_{\max , \mathrm{s}} \geq 54 \mathrm{~m} \mathrm{~s}^{-1}, 105$ knots) as well as strong typhoons $\left(P_{\mathrm{cs}} \leq 960 \mathrm{hPa}\right.$ or $V_{\max , \mathrm{s}} \geq 44 \mathrm{~m} \mathrm{~s}^{-1}, 85$ knots), that affect Zhanjiang (close to Haikou), Hong Kong (close to Shenzhen), Wenzhou and Ningbo within $500 \mathrm{~km}$ are extracted from the 65-year JMA dataset. It turns out that only two TCs (200814 Hagupit and 201409 Rammasun) 

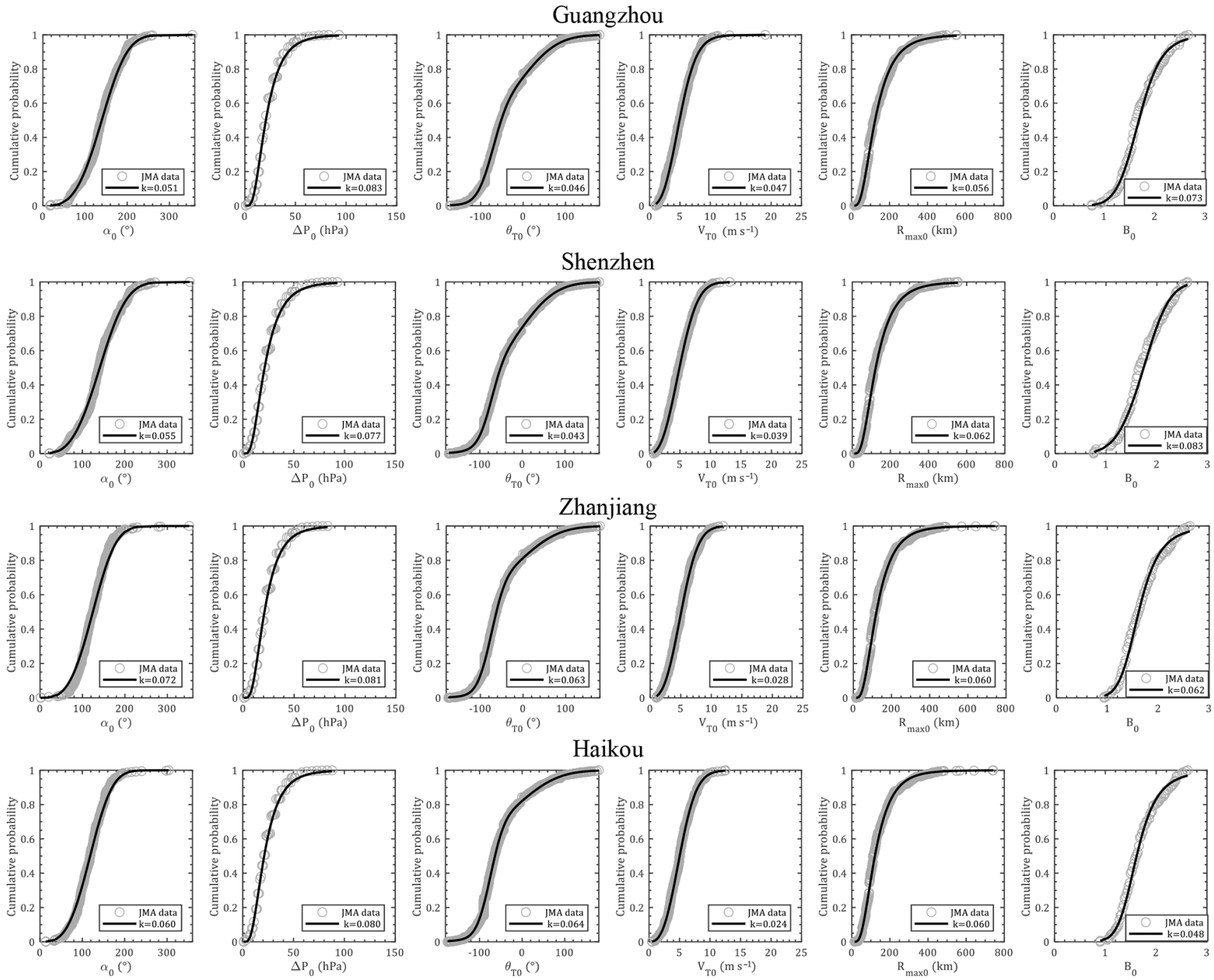

Figure 16. Empirical and preferable cumulative probability distributions for $\alpha_{0}, \Delta P_{0}, \theta_{0}, V_{\mathrm{T} 0}, R_{\max , \mathrm{s} 0}$ and $B_{\mathrm{s} 0}$.

Table 4. Comparison of TC design wind speed at selected cities (MRI $=100$ years; $\left.T=10 \mathrm{~min} ; z=10 \mathrm{~m}, z_{0}=0.05 \mathrm{~m} ; \mathrm{m} \mathrm{s}^{-1}\right)$.

\begin{tabular}{|c|c|c|c|c|c|c|c|c|}
\hline \multirow[t]{2}{*}{ City } & \multirow[t]{2}{*}{$\begin{array}{r}\text { JTG/T D60- } \\
01-2004\end{array}$} & \multirow[t]{2}{*}{$\begin{array}{r}\text { GB 5009- } \\
2012\end{array}$} & \multirow[t]{2}{*}{$\begin{array}{r}\text { Xiao et al. } \\
\text { (2011) }\end{array}$} & \multicolumn{2}{|c|}{$\begin{array}{l}\mathrm{Li} \text { and Hong } \\
\text { (2016) }\end{array}$} & \multirow[t]{2}{*}{$\begin{array}{r}\text { Chen and } \\
\text { Duan (2018) }\end{array}$} & \multirow[t]{2}{*}{$\begin{array}{r}\text { Wu and } \\
\text { Huang (2019) }\end{array}$} & \multirow[t]{2}{*}{$\begin{array}{l}\text { This } \\
\text { study }\end{array}$} \\
\hline & & & & CSM & FTM & & & \\
\hline Shanghai & 33.8 & 31.30 & 48.27 & 32.2 & 31.7 & 31.7 & 32.2 & 34.35 \\
\hline Ningbo & 31.3 & 31.30 & 44.93 & 33.3 & 33.0 & 34.5 & 33.9 & 35.33 \\
\hline Wenzhou & 33.8 & 33.81 & 48.75 & 36.1 & 36.5 & 34.9 & 36.9 & 39.21 \\
\hline Fuzhou & 37.4 & 37.25 & 48.47 & 37.8 & 35.1 & 33.6 & 36.5 & 37.41 \\
\hline Xiamen & 39.7 & 39.38 & 46.70 & 39.1 & 38.9 & 37.7 & 37.6 & 39.18 \\
\hline Guangzhou & 31.3 & 31.30 & 41.57 & 30.5 & 31.4 & - & 30.9 & 30.87 \\
\hline Shenzhen & 38.4 & 38.33 & 43.79 & 36.4 & 36.8 & 36.4 & 34.7 & 37.34 \\
\hline Hong Kong & 39.5 & 39.38 & 45.03 & 37.6 & 37.7 & - & 37.5 & 38.17 \\
\hline Zhanjiang & 39.4 & 39.38 & 42.86 & 40.9 & 37.4 & 37.5 & 38.7 & 33.92 \\
\hline Haikou & 38.4 & 38.33 & 42.94 & - & - & 38.5 & - & 34.52 \\
\hline
\end{tabular}



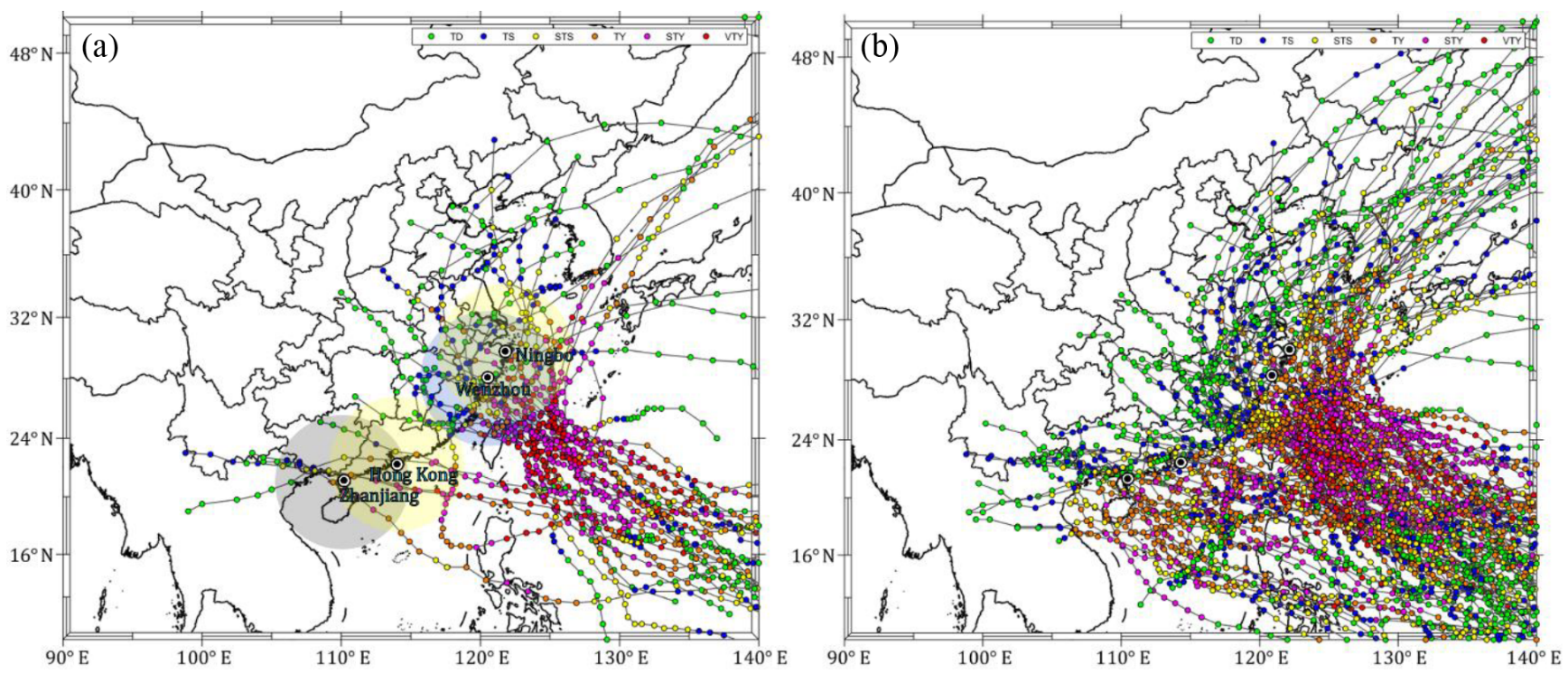

Figure 17. Strong typhoon tracks affect Ningbo, Wenzhou, Hong Kong and Zhanjiang: (a) violent typhoons $\left(P_{\mathrm{c}}<935 \mathrm{hPa}\right.$ or $V_{\mathrm{max}}>$ $\left.57 \mathrm{~m} \mathrm{~s}^{-1}\right)$; (b) strong typhoons $\left(P_{\mathrm{c}}<960 \mathrm{hPa}\right.$ or $\left.V_{\max }>43 \mathrm{~m} \mathrm{~s}^{-1}\right)$.

around Zhanjiang (or Haikou) and six TCs (195408 Ida, 197909 Hope, 200814 Hagupit, 201013 Megi, 201319 Usagi and 201409 Rammasun) around Hong Kong (or Shenzhen) reached the violent level. Comparatively, 25 and 13 violent typhoons were observed around Wenzhou and Ningbo, respectively. Moreover, 40 and 52 strong typhoons affected Zhanjiang and Hong Kong, respectively, while Wenzhou and Ningbo suffered 89 and 55 strong typhoons over the past half a century. This is thanks to the obstacle effects of several high mountains in the Philippines so that the violent typhoons making landfall in Hainan and Guangdong provinces usually need to reintensify in the South China Sea or directly pass through the Bashi Channel between Taiwan and the Philippines, so not many violent typhoons were observed to affect these two provinces. In addition, the maximum wind of the rotating storm in the Northern Hemisphere always occurs on its right side with respect to the heading direction due to the Coriolis effect. Thus, westward-heading violent typhoons seldom occur in Zhanjiang and Haikou before their intensities decay due to the effect of Hainan island. Instead, Hong Kong, Wenzhou or Ningbo have greater chances of being swept by a storm's maximum wind. Accordingly, the prediction results should be more reasonable with higher design wind speeds in Wenzhou and Ningbo than in Zhanjiang and Haikou. It is suggested that this trend should be validated in a future study using more TC observation data.

The results in Xiao et al. (2011) are higher than those in other studies or codes. There are three possible reasons for this. The first is the use of the Holland (2008) method in determining $B$ values. This method was developed from semiempirical relationships between the gradient and surface layer as discussed by Fang et al. (2018a). Another reason is the use of a $1000 \mathrm{~km}$ radius subregion, which would take into account many extremely violent typhoons over the distant sea before they are used for TC intensity modeling. The third one is the use of a surface roughness of $0.02 \mathrm{~m}$, which is smaller than the code-specified value associated with the terrain exposure B of $0.05 \mathrm{~m}$.

The estimated wind speeds in Shanghai, Ningbo and Wenzhou are $2-3 \mathrm{~m} \mathrm{~s}^{-1}$ higher than the equivalents in $\mathrm{Li}$ and Hong (2016), while Zhanjiang showed about a $7 \mathrm{~m} \mathrm{~s}^{-1}$ smaller result. The other five cities show a satisfactory comparison between results of this study and those of $\mathrm{Li}$ and Hong (2016). When they are compared with Chen and Duan (2018), who used an improved full-track model, the present estimations in Zhanjiang and Haikou are also about $4 \mathrm{~m} \mathrm{~s}^{-1}$ smaller, while the other cities show $1-4 \mathrm{~m} \mathrm{~s}^{-1}$ higher values. Except for the potential reasons analyzed above, it is worth mentioning that $\mathrm{Li}$ and Hong (2016) adopted CMA track data with a 2 min duration while Chen and Duan (2018) used a JTWC dataset with a 1 min duration. Some errors could be introduced by the time duration gaps for different datasets. The wind speeds predicted by $\mathrm{Wu}$ and Huang (2019) are similar to those estimated by $\mathrm{Li}$ and Hong (2016), which is mainly attributed to the use of the same best-track dataset as well as $R_{\max }$ and $B$ models.

Figure 18 illustrates design wind speed versus return period plots (hazard curves) based on simulations together with the suggested values in Chinese codes (JTG/T D60-01-2004) for nine coastal cities. It can be seen that the predicted curves for Shanghai, Fuzhou, Xiamen, Guangzhou and Shenzhen are in satisfactory agreement with code suggestions. But, consistent with previous findings, this study shows higher estimations for Ningbo and Wenzhou, while it shows smaller 

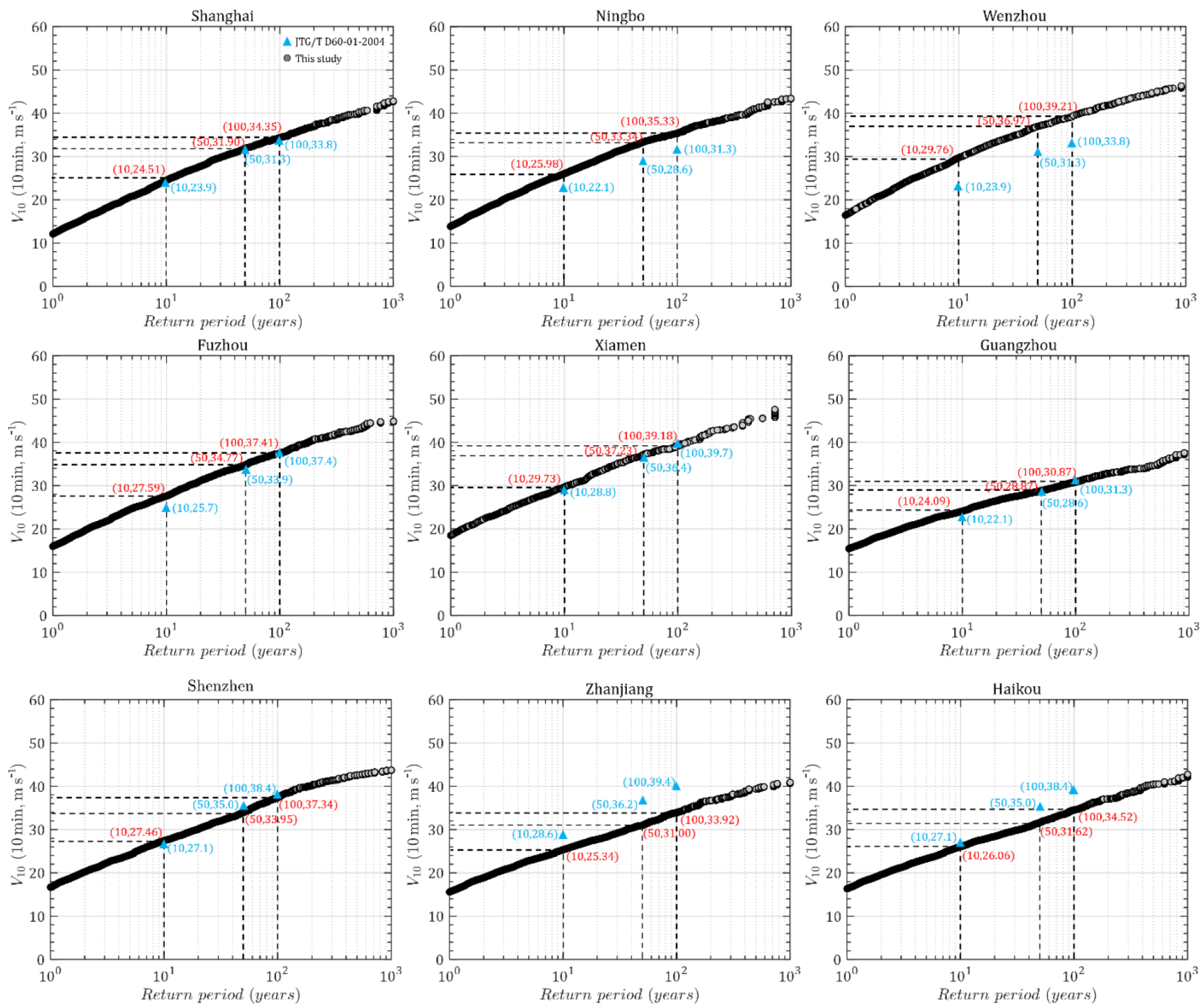

Figure 18. Predicted and code-suggested TC design wind speed versus return period of nine coastal cities in China.

estimations for Zhanjiang and Haikou than the code. It is also found that the estimated hazard curves for Ningbo and Wenzhou have a similar trend to the code, but the design wind speeds for Zhanjiang and Haikou increase more gently with return period than the code provisions. This is closely related to the portion of TC wind samples as well as their contributions to the description of the probabilistic distribution of extreme winds in a series of largest observed annual winds as discussed above. The TC winds in Ningbo and Wenzhou could dominate the probabilistic behavior of the yearly highest wind speed, while Zhanjiang and Haikou have lower portions of TC winds compared to non-TC winds. However, the contributions of strong TC winds will be overused in modeling the hazard curve when they are combined with smaller non-TC winds in the yearly largest wind series. More observations on TC winds and unique descriptions of the proba- bilistic behavior of TC winds are necessary to model sitespecific TC hazards and validate the long-term hazard predictions in this study.

\section{Conclusions}

The statistical characteristics of TC track as well as wind field parameters within a site-specific circular subregion extracted from the JMA best-track dataset were examined before developing TC wind speed hazard curves for 10 coastal cities in China using a height-resolving wind field model and a Monte Carlo technique. Some improvements and new findings are summarized as follows:

1. Recursive models are applied for both track (translation speed) and wind field ( $R_{\max , \mathrm{s}}$ and $\left.B_{\mathrm{s}}\right)$ parameters, 
which enable the movement as well as the size and wind field scale of a TC to vary smoothly. $R_{\mathrm{max}, \mathrm{s}}$ and $B_{\mathrm{S}}$ of the historical dataset are determined from the present height-resolving wind field model coupled with $10 \mathrm{~min}$ duration wind information provided by the JMA. Thus, the present study is self-adaptive, and no other statistical models of wind field parameters, which are commonly used in combination in other studies, are adopted. Meanwhile, the documented $R_{\mathrm{max}, \mathrm{s}}$ and $B_{\mathrm{s}}$ dataset facilitates the completeness of correlation studies between various parameters at first time steps before generating statistically correlated parameters using the Cholesky decomposition method.

2. The probabilistic behavior of TC track and wind model parameters of the first time steps (genesis parameters) within a $500 \mathrm{~km}$ circular subregion of 10 coastal cities is investigated and modeled with some preferable probability distribution models. Then the coefficients of the decay model as well as the recursive models for translation speed, $R_{\mathrm{max}, \mathrm{s}}$ and $B_{\mathrm{S}}$ in these 10 cities are also fitted.

3. The TC design wind speed versus return period plots (hazard curve) are developed from 10000-year Monte Carlo simulations and compared with code suggestions as well as other studies. It is found that the predicted wind speeds in northern cities (Ningbo and Wenzhou) are higher than code suggestions, while those of southern cities (Zhanjiang and Haikou) are smaller. The other six cities show satisfactory agreement with code provisions. Some potential reasons for this are discussed to emphasize the importance of independently developing hazard curves of TC and non-TC winds.

Data availability. All data that support the findings of this study are available from the corresponding author by request.

Author contributions. GF performed the simulations and data analyses. LiZ developed the methodology. GF and LiZ wrote the original draft. SC and LeZ reviewed and edited the manuscript. YG guided intellectual direction of the research.

Competing interests. The authors declare that they have no conflict of interest.

Acknowledgements. The authors gratefully acknowledge the support of the National Key Research and Development Program of China (2018YFC0809600, 2018YFC0809604) and the National Natural Science Foundation of China (51678451, 51778495).
Financial support. This research has been supported by the National Key Research and Development Program of China (grant nos. 2018YFC0809600 and 2018YFC0809604) and the National Natural Science Foundation of China (grant nos. 51678451 and 51778495).

Review statement. This paper was edited by Mauricio Gonzalez and reviewed by two anonymous referees.

\section{References}

Apsley, D. D.: Numerical Modeling of Neutral and Stably Stratified Flow and Dispersion in Complex Terrain, PhD Thesis, Faculty of Engineering, University of Surrey, Guildford, Surrey, UK, 1995.

Arthur, W. C.: A statistical-parametric model of tropical cyclones for hazard assessment, Nat. Hazards Earth Syst. Sci. Discuss., https://doi.org/10.5194/nhess-2019-192, in review, 2019.

ASCE STANDARD: ASCE/SEI 7-16, Minimum Design Loads for Buildings and Other Structures, American Society of Civil Engineers, Reston, Virginia, USA, 2017.

Batts, M. E., Russell, L. R., and Simiu, E.: Hurricane wind speeds in the United States, J. Struct. Div.-ASCE, 106, 2001-2016, 1980.

Buildings Department: Code of Practice on Wind Effects in Hong Kong 2004, The Government of the Hong Kong Special Administrative Region, Hong Kong, 2004a.

Buildings Department: Explanatory Materials to the Code of Practice on Wind Effects in Hong Kong 2004, The Government of the Hong Kong Special Administrative Region, Hong Kong, 2004b.

Chen, Y. and Duan, Z.: A statistical dynamics track model of tropical cyclones for assessing typhoon wind hazard in the coast of southeast China, J. Wind Eng. Ind. Aerod., 172, 325-340, 2018.

China Trade Standard: JTG/T D60-01-2004: Wind-resistant design specification for highway bridges, China Communications Press, Beijing, China, 2004.

China National Standard: GB 50009-2012: Load code for the design of building structures, National Standards Committee, Beijing, China, 2012.

Done, J. M., Ge, M., Holland, G. J., Dima-West, I., Phibbs, S., Saville, G. R., and Wang, Y.: Modelling global tropical cyclone wind footprints, Nat. Hazards Earth Syst. Sci., 20, 567-580, https://doi.org/10.5194/nhess-20-567-2020, 2020.

Dvorak, V. F.: Tropical cyclone intensity analysis using satellite data, NOAA Technical Report, NESDIS 11, US Department of Commerce, National Oceanic and Atmospheric Administration, National Environ-mental Satellite, Data, and Information Service, Washington, D.C., USA, available at: http://severeweather. wmo.int/TCFW/RAI_Training/Dvorak_1984.pdf (last access: 2 June 2020), 1984.

Fang, G., Zhao, L., Cao, S., Ge, Y., and Pang W.: A novel analytical model for wind field simulation under typhoon boundary layer considering multi-field correlation and height-dependency, J. Wind Eng. Ind. Aerod., 175, 77-89, 2018a.

Fang, G., Zhao, L., Song, L., Liang X., Zhu L., Cao S., and Ge Y.: Reconstruction of radial parametric pressure field near ground surface of landing typhoons in Northwest Pacific Ocean, J. Wind Eng. Ind. Aerod., 183, 223-234, 2018 b. 
Fang, G., Zhao, L., Cao, S., Ge, Y., and Li, K.: Gust Characteristics of near-ground typhoon winds, J. Wind Eng. Ind. Aerod., 188, 323-337, 2019a.

Fang, G., Pang, W., Zhao, L., Cao, S., and Ge, Y.: Towards a refined estimation of typhoon wind hazards: Parametric modelling and upstream terrain effects, The 15th International Conference on Wind Engineering, 1-6 September 2019, Beijing, China, 2019 b.

Federal Emergency Management Agency (FEMA): Multi-Hazard Loss Estimation Methodology, Hurricane Model, HAZUS ${ }^{\circledR}$ MH2.1, Technical Manual. Federal Emergency Management Agency, Washington, D.C., USA, 2015.

Georgiou, P. N.: Design wind speeds in tropical cyclone-prone regions, $\mathrm{PhD}$ Thesis, Faculty of Engineering Science, University of Western Ontario, London, Ontario, Canada, 1985.

Holland, G. J.: An analytic model of the wind and pressure profiles in hurricanes, Mon. Weather Rev., 108, 1212-1218, 1980.

Holland, G. J.: A Revised Hurricane Pressure-Wind Model, Mon. Weather Rev., 136, 3432-3445, 2008.

Iman, R. L. and Conover, W. J.: A distribution-free approach to inducing rank correlation among input variables, Commun. Stat.Simul. C., 11, 311-334, 1982.

Kepert, J. D.: Slab- and height-resolving models of the tropical cyclone boundary layer. Part I: Comparing the simulations, Q. J. Roy. Meteor. Soc., 136, 1700-1711, 2010.

Knapp, K. R., Kruk, M. C., Levinson, D. H., Diamond, H. J., and Neumann, C. J.: The International Best Track Archive for Climate Stewardship (IBTrACS): Unifying Tropical Cyclone Data, B. Am. Meteorol. Soc., 91, 363-376, 2010.

Kwok, K. C. S., Kot, S. C., and Ng, E.: Wind Code, Air Quality Standards and Air Ventilation Assessment for Hong Kong - Latest Developments, in: 3rd Workshop on Regional Harmonization of Wind Loading and Wind Environmental Specifications in Asia-Pacific Economies (APEC-WW 2006), 2-3 November 2006, New Delhi, India, 25-38, 2006.

Li, S. and Hong, H.: Use of historical best track data to estimate typhoon wind hazard at selected sites in China, Nat. Hazards, 76, 1395-1414, 2015.

Li, S. and Hong, H.: Typhoon wind hazard estimation for China using an empirical track model, Nat. Hazards, 82, 1009-1029, 2016.

Liu, D., Pang, L., and Xie B.: Typhoon disaster in China: prediction, prevention, and mitigation, Nat. Hazards, 49, 421-436, 2009.

Meng, Y., Matsui, M., and Hibi, K.: An analytical model for simulation of the wind field in a typhoon boundary layer, J. Wind Eng. Ind. Aerod., 56, 291-310, 1995.

Nederhoff, K., Giardino, A., van Ormondt, M., and Vatvani, D.: Estimates of tropical cyclone geometry parameters based on best-track data, Nat. Hazards Earth Syst. Sci., 19, 2359-2370, https://doi.org/10.5194/nhess-19-2359-2019, 2019.

RSMC Tokyo-Typhoon Center: Best Track Data (19512015), Japan Meteorological Agency (JMA), available at: https://www.jma.go.jp/jma/jma-eng/jma-center/ rsmc-hp-pub-eg/besttrack.html (last access: 3 March 2019), 2018.

Russell, L. and Schueller, G.: Probabilistic models for Texas gulf coast hurricane occurrences, J. Petrol. Technol., 26, 279-288, 1974.
Simiu, E. and Scanlan, R. H.: Wind Effects on Structures: Fundamentals and Applications to Design, 3rd edn., J. Wiley and Sons, New York, USA, Chichester, UK, Brisbane, Australia, 1996.

Snaiki, R. and Wu, T.: Modeling tropical cyclone boundary layer: Height-resolving pressure and wind fields, J. Wind Eng. Ind. Aerod., 170, 18-27, 2017.

Song, J., Wang, Y., and Wu, L.: Trend discrepancies among three best track data sets of western North Pacific tropical cyclones, J. Geophys. Res.-Atmos., 115, D12128, https://doi.org/10.1029/2009JD013058, 2010.

Tao, T. and Wang, H.: Modelling of longitudinal evolutionary power spectral density of typhoon winds considering highfrequency subrange, J. Wind Eng. Ind. Aerod., 193, 103957, https://doi.org/10.1016/j.jweia.2019.103957, 2019.

Tao, T., Wang, H., and Kareem, A.: Reduced-Hermite bifoldinterpolation assisted schemes for the simulation of random wind field, Probabilist. Eng. Mech., 53, 126-142, 2018.

Velden, C., Harper, B., Wells, F., Beven II, J. L., Zehr, R., Olander, T., Mayfield, M., Guard, C. C., Lander, M., Edson, R., Avila, L., Burton., A., Turk, M., Kikuchi, A., Christian, A., Caroff, P., and McCrone, P.: The Dvorak Tropical Cyclone Intensity Estimation Technique: A Satellite-Based Method that Has Endured for over 30 Years, B. Am. Meteorol. Soc., 87, 1195-1210, 2006.

Vickery, P. J.: Simple Empirical Models for Estimating the Increase in the Central Pressure of Tropical Cyclones after Landfall along the Coastline of the United States, J. Appl. Meteorol., 44, 18071826, 2005.

Vickery, P. J. and Twisdale, L. A.: Prediction of Hurricane Wind Speeds in the United States, J. Struct. Eng., 121, 1691-1699, 1995.

Vickery, P. J. and Wadhera, D.: Statistical Models of Holland Pressure Profile Parameter and Radius to Maximum Winds of Hurricanes from Flight-Level Pressure and $\mathrm{H}^{*}$ Wind Data, J. Appl. Meteorol. Clim., 47, 2497-2517, 2008.

Vickery, P. J., Skerlj, P. F., Steckley, A. C., and Twisdale, L. A.: Hurricane Wind Field Model for Use in Hurricane Simulations, J. Struct. Eng., 126, 1203-1221, 2000a.

Vickery, P. J., Skerlj, P. F., and Twisdale, L. A.: Simulation of Hurricane Risk in the U.S. Using Empirical Track Model, J. Struct. Eng., 126, 1222-1237, 2000b.

Vickery, P. J., Wadhera, D., Powell, M. D., and Chen, Y.: A Hurricane Boundary Layer and Wind Field Model for Use in Engineering Applications, J. Appl. Meteorol. Clim., 48, 381-405, 2009.

Wu, F. and Huang, G.: Refined empirical model of typhoon wind field and its application in China, J. Struct. Eng., 145, 04019122, https://doi.org/10.1061/(ASCE)ST.1943-541X.0002422, 2019.

Xiao, Y., Duan, Z., Xiao, Y., Ou J., Chang, L., and Li Q.: Typhoon wind hazard analysis for southeast China coastal regions, Struct. Saf., 33, 286-295, 2011.

Yang, J. and Chen, M.: Landfalls of Tropical Cyclones with Rapid Intensification in the Western North Pacific, Nat. Hazards Earth Syst. Sci. Discuss., https://doi.org/10.5194/nhess-2019-279, in review, 2019.

Ying, M., Zhang, W., Yu, H., Lu, X., Feng, J., Fan, Y., Zhu, Y., and Chen, D.: An Overview of the China Meteorological Administration Tropical Cyclone Database, J. Atmos. Ocean. Tech., 31, 287-301, 2014. 
Yuan, J., Wang, D., Wan, Q., and Liu, C.: A 28-year climatological analysis of size parameters for Northwestern Pacific tropical cyclones, Adv. Atmos. Sci., 24, 24-34, 2007.
Zhao, L., Lu, A., Zhu, L., Cao, S., and Ge, Y.: Radial pressure profile of typhoon field near ground surface observed by distributed meteorologic stations, J. Wind Eng. Ind. Aerod., 122, 105-112, 2013. 